\title{
Facile Synthesis of Nitrogen-Containing Six-Membered Benzofuzed Phenophosphazinine Oxides and Studies of the Photophysical Properties
}

Wenqiang Ye, Xiaobin Li, Bingbing Ding, Chenchen Wang, Mohini Shrestha, Xiang Ma, Yifeng Chen, * He Tian

Key Laboratory for Advanced Materials and Feringa Nobel Prize Scientist Joint Research Center, School of Chemistry and Molecular Engineering, East China University of Science \& Technology.130 Meilong Road, Shanghai, 200237, China.

*Email: yifengchen@ecust.edu.cn.

\section{Supporting Information}

X-ray Crystallography S2-S4

Time-Dependent DFT calculation S5-S7

UV-vis absorption and emission of phosphole oxides S8

NMR Spectra S9-S59 


\section{X-ray Crystallography}

Single crystals suitable for X-ray crystal analysis were obtained by slow evaporation petroleum ether to a solution of 2a in DCM or slow evaporation pentane to a solution of $\mathbf{2 a a}$ in $\mathrm{CHCl}_{3}$ at room temperature. Details of crystal data and structural refinements are given.

X-ray crystallographic data of compound (2a). (CCDC 1949302)

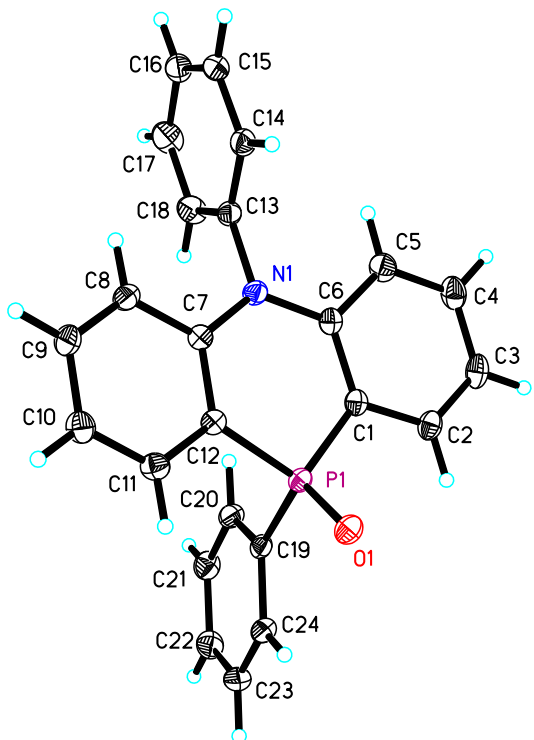

ORTEP of 2a showing thermal ellipsoids at the $30 \%$ probability level.

Single crystal X-ray diffraction data was collected at 193(2) K for 2a on a Bruker D8 Venture diffractometer.

Crystal data and structure refinement for $\mathbf{2 a}$.

Identification code

Empirical formula

Formula weight

Temperature

Wavelength

Crystal system

Space group

Unit cell dimensions

Volume

Z

Density (calculated)

Absorption coefficient

$\mathrm{F}(000)$

Crystal size

Theta range for data collection mo_d8v19599_0m

C24 H18 N O P

367.36

193(2) K

$0.71073 \AA$

Monoclinic

P 21/n

$\mathrm{a}=11.0843(3) \AA \quad \alpha=90^{\circ}$.

$\mathrm{b}=9.0065(2) \AA$

$\beta=92.3640(10)^{\circ}$.

$\mathrm{c}=18.6072(5) \AA$ $\gamma=90^{\circ}$.
4

$1.315 \mathrm{Mg} / \mathrm{m}^{3}$

$0.161 \mathrm{~mm}^{-1}$

\section{8}

$0.200 \times 0.160 \times 0.140 \mathrm{~mm}^{3}$

2.513 to $25.999^{\circ}$. 
Index ranges

Reflections collected

Independent reflections

Completeness to theta $=25.242^{\circ}$

Absorption correction

Max. and min. transmission

Refinement method

Data / restraints / parameters

Goodness-of-fit on $\mathrm{F}^{2}$

Final $\mathrm{R}$ indices [I $>2 \operatorname{sigma}(\mathrm{I})]$

$\mathrm{R}$ indices (all data)

Extinction coefficient

Largest diff. peak and hole $-13<=\mathrm{h}<=13,-11<=\mathrm{k}<=11,-22<=\mathrm{l}<=22$

18419

$3628[\mathrm{R}(\mathrm{int})=0.0298]$

$99.4 \%$

Semi-empirical from equivalents

0.7456 and 0.6671

Full-matrix least-squares on $\mathrm{F}^{2}$

$3628 / 0 / 244$

1.051

$\mathrm{R} 1=0.0338, \mathrm{wR} 2=0.0841$

$\mathrm{R} 1=0.0396, \mathrm{wR} 2=0.0886$

0.324 and -0.331 e. $\AA^{-3}$

X-ray crystallographic data of compound (2aa). (CCDC 1949301)
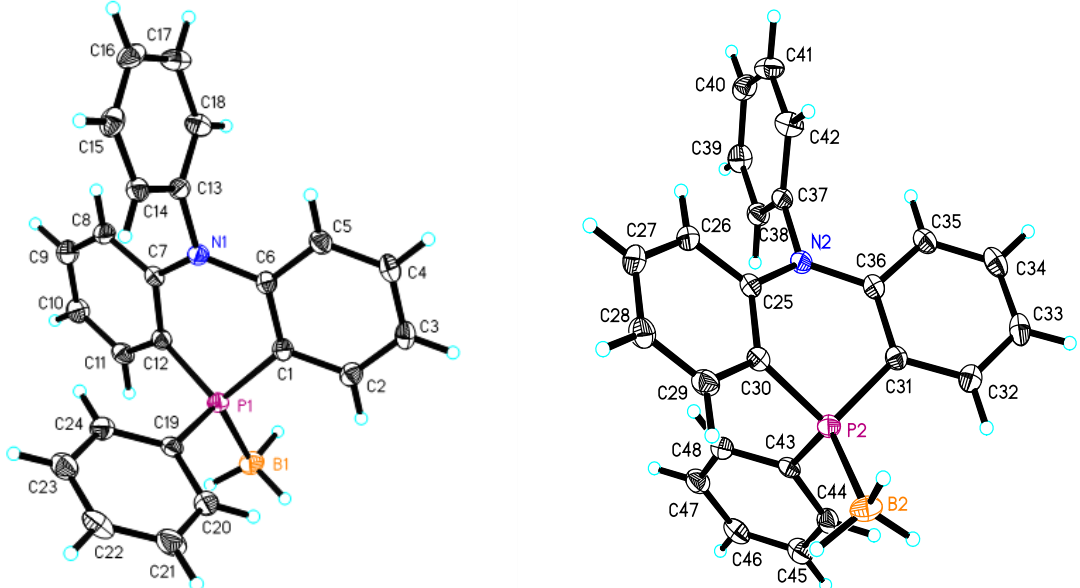

ORTEP of 2aa showing thermal ellipsoids at the $30 \%$ probability level.

Single crystal X-ray diffraction data was collected at 193(2) K for 2aa on a Bruker D8 Venture diffractometer.

Crystal data and structure refinement for $\mathbf{2 a a}$.

Identification code

Empirical formula

Formula weight

Temperature

Wavelength

Crystal system

Space group

Unit cell dimensions mo_d8v19665_0m

C24 H21 B N P

365.20

193(2) K

$0.71073 \AA$

Monoclinic

P 21/c

$\mathrm{a}=9.4685(2) \AA \quad \alpha=90^{\circ}$.

$\mathrm{b}=18.8225(4) \AA \quad \beta=94.8090(10)^{\circ}$.

$\mathrm{c}=21.6751(4) \AA \quad \gamma=90^{\circ}$. 
Volume

Z

Density (calculated)

Absorption coefficient

$\mathrm{F}(000)$

Crystal size

Theta range for data collection

Index ranges

Reflections collected

Independent reflections

Completeness to theta $=25.242^{\circ}$

Absorption correction

Max. and min. transmission

Refinement method

Data / restraints / parameters

Goodness-of-fit on $\mathrm{F}^{2}$

Final $\mathrm{R}$ indices [I $>2 \operatorname{sigma}(\mathrm{I})]$

$\mathrm{R}$ indices (all data)

Extinction coefficient

Largest diff. peak and hole
3849.36(14) $\AA^{3}$

8

$1.260 \mathrm{Mg} / \mathrm{m}^{3}$

$0.151 \mathrm{~mm}^{-1}$

1536

$0.200 \times 0.160 \times 0.130 \mathrm{~mm}^{3}$

2.361 to $25.496^{\circ}$.

$-11<=\mathrm{h}<=11,-22<=\mathrm{k}<=22,-26<=1<=23$

37607

$7164[\mathrm{R}(\mathrm{int})=0.0493]$

$99.8 \%$

Semi-empirical from equivalents

0.7456 and 0.6884

Full-matrix least-squares on $\mathrm{F}^{2}$

7164 / 0 / 512

1.021

$\mathrm{R} 1=0.0456, \mathrm{wR} 2=0.1055$

$\mathrm{R} 1=0.0654, \mathrm{wR} 2=0.1208$

$0.0016(5)$

0.557 and -0.278 e. $\AA^{-3}$ 


\section{Time-Dependent DFT calculation(B3LYP/6-31+G(d) - level of theory)}

Table S1 Time-Dependent DFT calculation of 2a and $\mathbf{2 e .}$

\begin{tabular}{|c|c|c|c|}
\hline Compound & $\begin{array}{l}\text { Transitions (contribution } \\
/ \%)\end{array}$ & $\begin{array}{l}\text { Wavelength /nm } \\
(\text { Energy / eV)) }\end{array}$ & Oscillator strength \\
\hline \multirow[t]{4}{*}{$2 \mathbf{a}^{\mathrm{a}}$} & HOMO $\rightarrow$ LUMO $(96 \%)$ & $320.96(3.86)$ & 0.1224 \\
\hline & $\mathrm{HOMO} \rightarrow \mathrm{LUMO}+1(97 \%)$ & $311.72(3.98)$ & 0.1259 \\
\hline & $\mathrm{HOMO} \rightarrow \mathrm{LUMO}+2(15 \%)$ & $297.08(4.17)$ & 0.0001 \\
\hline & $\mathrm{HOMO} \rightarrow \mathrm{LUMO}+3(84 \%)$ & & \\
\hline \multirow[t]{6}{*}{$2 \mathrm{e}^{\mathrm{a}}$} & HOMO $\rightarrow$ LUMO $(96 \%)$ & $364.88(3.40)$ & 0.2311 \\
\hline & HOMO- $1 \rightarrow$ LUMO $(10 \%)$ & $343.37(3.61)$ & 0.0721 \\
\hline & $\mathrm{HOMO} \rightarrow \mathrm{LUMO}+2(87 \%)$ & & \\
\hline & HOMO-2 $\rightarrow$ LUMO (4\%) & $312.65(3.97)$ & 0.0631 \\
\hline & HOMO- $1 \rightarrow$ LUMO (7\%) & & \\
\hline & $\mathrm{HOMO} \rightarrow \mathrm{LUMO}+3(81 \%)$ & & \\
\hline
\end{tabular}

The number of imaginary frequencies is 0 .

Absolute energy values:

E2as 1 =-1396.69577641

$\mathrm{E} 2 \mathrm{as} 0=-1396.82859661$

E2es1 $=-1512.25723804$

$\mathrm{E} 2 \mathrm{es} 0=-1512.36833000$

The optimized geometry of 2a is shown below in cartesian coordinates:

\begin{tabular}{lccc}
\hline $\mathrm{C}$ & -1.60847200 & 2.43246400 & 0.00083700 \\
$\mathrm{C}$ & -1.01973600 & 3.68718500 & 0.08800700 \\
$\mathrm{C}$ & -0.86202300 & 1.24971000 & 0.23283900 \\
$\mathrm{C}$ & 0.33677300 & 3.82749300 & 0.41067000 \\
$\mathrm{C}$ & 1.07872000 & 2.67957500 & 0.65160100 \\
$\mathrm{C}$ & 0.50657900 & 1.39422900 & 0.57046700 \\
$\mathrm{C}$ & -1.60824400 & -2.43256900 & 0.00047100 \\
$\mathrm{C}$ & -1.01940100 & -3.68725700 & 0.08750500 \\
$\mathrm{C}$ & 0.33708600 & -3.82748100 & 0.41026900 \\
$\mathrm{C}$ & 1.07891300 & -2.67952600 & 0.65142400 \\
$\mathrm{C}$ & 0.50666300 & -1.39422800 & 0.57044300 \\
$\mathrm{C}$ & -0.86192500 & -1.24979400 & 0.23272100 \\
$\mathrm{H}$ & -2.65872200 & -2.36976200 & -0.25184500 \\
$\mathrm{H}$ & -1.63044800 & -4.56638500 & -0.10189600 \\
$\mathrm{H}$ & 0.79729100 & -4.80918200 & 0.47597300 \\
$\mathrm{H}$ & 2.13073700 & -2.76708200 & 0.91479300 \\
$\mathrm{~N}$ & -1.49931900 & -0.00004700 & 0.11284800 \\
$\mathrm{P}$ & 1.55038300 & 0.00004100 & 1.02529200 \\
$\mathrm{O}$ & 2.01566100 & 0.00006100 & 2.47019400 \\
$\mathrm{C}$ & 2.98896100 & 0.00006800 & -0.11039900
\end{tabular}




\begin{tabular}{lrrr}
\hline $\mathrm{C}$ & 2.81992600 & 0.00078900 & -1.50476700 \\
$\mathrm{C}$ & 4.28349600 & -0.00059400 & 0.42806100 \\
$\mathrm{C}$ & 3.93252200 & 0.00080900 & -2.34828300 \\
$\mathrm{H}$ & 1.81999600 & 0.00129800 & -1.93281700 \\
$\mathrm{C}$ & 5.39775400 & -0.00056700 & -0.41845500 \\
$\mathrm{H}$ & 4.41398300 & -0.00113000 & 1.50656700 \\
$\mathrm{C}$ & 5.22352200 & 0.00014900 & -1.80533900 \\
$\mathrm{H}$ & 3.79349300 & 0.00134700 & -3.42654500 \\
$\mathrm{H}$ & 6.39852200 & -0.00108600 & 0.00648300 \\
$\mathrm{H}$ & 6.08928800 & 0.00019700 & -2.46317100 \\
$\mathrm{H}$ & -2.65896800 & 2.36959300 & -0.25140300 \\
$\mathrm{H}$ & -1.63088500 & 4.56628600 & -0.10119400 \\
$\mathrm{H}$ & 0.79688800 & 4.80922900 & 0.47648800 \\
$\mathrm{H}$ & 2.13055700 & 2.76716500 & 0.91490600 \\
$\mathrm{C}$ & -2.91471800 & -0.00007600 & -0.19546800 \\
$\mathrm{C}$ & -3.84802800 & -0.00034000 & 0.84461800 \\
$\mathrm{C}$ & -3.33667400 & 0.00018100 & -1.52822400 \\
$\mathrm{C}$ & -5.21443900 & -0.00036600 & 0.54751400 \\
$\mathrm{H}$ & -3.50302800 & -0.00052700 & 1.87525000 \\
$\mathrm{C}$ & -4.70345200 & 0.00014600 & -1.82104200 \\
$\mathrm{H}$ & -2.59831800 & 0.00041500 & -2.32591200 \\
$\mathrm{C}$ & -5.64329800 & -0.00012400 & -0.78417400 \\
$\mathrm{H}$ & -5.94097300 & -0.00056800 & 1.35608900 \\
$\mathrm{H}$ & -5.03229800 & 0.00033600 & -2.85708900 \\
$\mathrm{H}$ & -6.70594600 & -0.00015400 & -1.01331500
\end{tabular}

The optimized geometry of $2 \mathrm{e}$ is shown below in cartesian coordinates:

\begin{tabular}{lrrr}
\hline $\mathrm{C}$ & -4.22164500 & 2.00343500 & -1.51022700 \\
$\mathrm{C}$ & -2.95301500 & 2.06107400 & -0.95972500 \\
$\mathrm{C}$ & -2.38850800 & 0.95178600 & -0.27982400 \\
$\mathrm{C}$ & -3.12117700 & -0.26851500 & -0.23540400 \\
$\mathrm{C}$ & -4.42568100 & -0.29171100 & -0.78760000 \\
$\mathrm{C}$ & -4.97538100 & 0.82146700 & -1.40057400 \\
$\mathrm{C}$ & -1.03250600 & 1.01458600 & 0.26733000 \\
$\mathrm{C}$ & -2.49544100 & -1.46310700 & 0.31807900 \\
$\mathrm{C}$ & -1.11190700 & -1.41725000 & 0.65824700 \\
$\mathrm{C}$ & -0.37156000 & -0.16609400 & 0.57144000 \\
$\mathrm{C}$ & -0.50631900 & -2.59659100 & 1.16580400 \\
$\mathrm{H}$ & 0.53153700 & -2.57972500 & 1.47598900 \\
$\mathrm{C}$ & -1.22332900 & -3.77006400 & 1.32653200 \\
$\mathrm{C}$ & -2.58813700 & -3.81096500 & 0.99181500 \\
$\mathrm{C}$ & -3.20667200 & -2.67304200 & 0.50063000 \\
$\mathrm{H}$ & -4.62408400 & 2.86533600 & -2.03603800 \\
$\mathrm{H}$ & -2.36992800 & 2.96518400 & -1.08275800
\end{tabular}




\begin{tabular}{lrrr}
\hline $\mathrm{H}$ & -5.00649800 & -1.20657800 & -0.75984000 \\
$\mathrm{H}$ & -5.97610600 & 0.76827000 & -1.82167100 \\
$\mathrm{H}$ & -0.73007900 & -4.65183600 & 1.72763700 \\
$\mathrm{H}$ & -3.16012900 & -4.72541600 & 1.12622600 \\
$\mathrm{H}$ & -4.26366400 & -2.72012300 & 0.26296800 \\
$\mathrm{C}$ & 1.35823400 & 3.86449200 & 0.05824300 \\
$\mathrm{C}$ & 2.70921800 & 4.13848400 & -0.12175800 \\
$\mathrm{C}$ & 3.66123700 & 3.10930500 & -0.08788700 \\
$\mathrm{C}$ & 3.23485700 & 1.80804300 & 0.15096500 \\
$\mathrm{C}$ & 1.87268900 & 1.50995300 & 0.34593800 \\
$\mathrm{C}$ & 0.91241500 & 2.54046800 & 0.27577200 \\
$\mathrm{H}$ & 0.64171800 & 4.67639700 & 0.00265700 \\
$\mathrm{H}$ & 3.02121900 & 5.16416600 & -0.30279400 \\
$\mathrm{H}$ & 4.71579900 & 3.32471300 & -0.23537000 \\
$\mathrm{H}$ & 3.96648400 & 1.00527800 & 0.20582800 \\
$\mathrm{~N}$ & -0.46231500 & 2.29521800 & 0.40503200 \\
$\mathrm{C}$ & -1.24688300 & 3.33811600 & 1.10427200 \\
$\mathrm{H}$ & -1.48058300 & 4.19371700 & 0.46358300 \\
$\mathrm{H}$ & -2.18073300 & 2.90938600 & 1.46531700 \\
$\mathrm{H}$ & -0.67498300 & 3.69027200 & 1.96971400 \\
$\mathrm{P}$ & 1.41523100 & -0.14720000 & 0.89347100 \\
$\mathrm{C}$ & 2.19794400 & -1.29199300 & -0.31008500 \\
$\mathrm{C}$ & 1.88185900 & -1.24964600 & -1.67743000 \\
$\mathrm{C}$ & 3.16119800 & -2.20200700 & 0.14773000 \\
$\mathrm{C}$ & 2.51683500 & -2.11331400 & -2.57271500 \\
$\mathrm{H}$ & 1.13948600 & -0.54535500 & -2.04577400 \\
$\mathrm{C}$ & 3.79970800 & -3.06347800 & -0.75052900 \\
$\mathrm{H}$ & 3.40420500 & -2.23511900 & 1.20618400 \\
$\mathrm{C}$ & 3.47703900 & -3.02129800 & -2.11023800 \\
$\mathrm{H}$ & 2.26317500 & -2.07775400 & -3.62930700 \\
$\mathrm{H}$ & 4.54551200 & -3.76610000 & -0.38685900 \\
$\mathrm{H}$ & 3.97092800 & -3.69261400 & -2.80852200 \\
$\mathrm{O}$ & 1.84800400 & -0.47417600 & 2.31159300
\end{tabular}




\section{UV-vis absorption and emission of dibenzophosphole oxides}

Table S2 Photophysical data for the Phosphacycles $2^{\mathrm{a}}$.

\begin{tabular}{ccccccc}
\hline & $\lambda_{\text {max }}(\mathrm{nm})^{a}$ & $\log _{\varepsilon}(\%)$ & $\lambda_{\mathrm{em}}(\mathrm{nm})^{a}$ & $\Phi(\%)^{b}$ & $\lambda_{\mathrm{em}}(\mathrm{nm})^{c}$ & $\Phi(\%)^{d}$ \\
\hline $\mathbf{2 a}$ & 344 & 4.18 & 427 & 0.5 & 445 & 2.8 \\
$\mathbf{2 b}$ & 346 & 4.11 & 436 & 0.7 & 463 & - \\
$\mathbf{2 c}$ & 351 & 4.40 & 413 & 0.9 & 462 & - \\
$\mathbf{2 d}$ & 372 & 3.78 & 433 & 51.5 & 457 & 15.1 \\
$\mathbf{2 e}$ & 351 & 4.03 & 413 & 1.4 & 449 & - \\
$\mathbf{2 f}$ & 360 & 3.88 & 401 & 3.7 & 453 & - \\
$\mathbf{2 g}$ & 330 & 4.41 & 397 & 4.2 & 445 & - \\
$\mathbf{2 h}$ & 349 & 4.16 & 398 & 0.9 & 450 & - \\
\hline
\end{tabular}

[a] In DCM. [b] Relative fluorescence quantum yield in DCM, those value was obtained in DCM solution relative to quinine sulfate. [c] In neat film. [d] Absolute fluorescence quantum yield in neat film. 


\section{NMR Spectra}

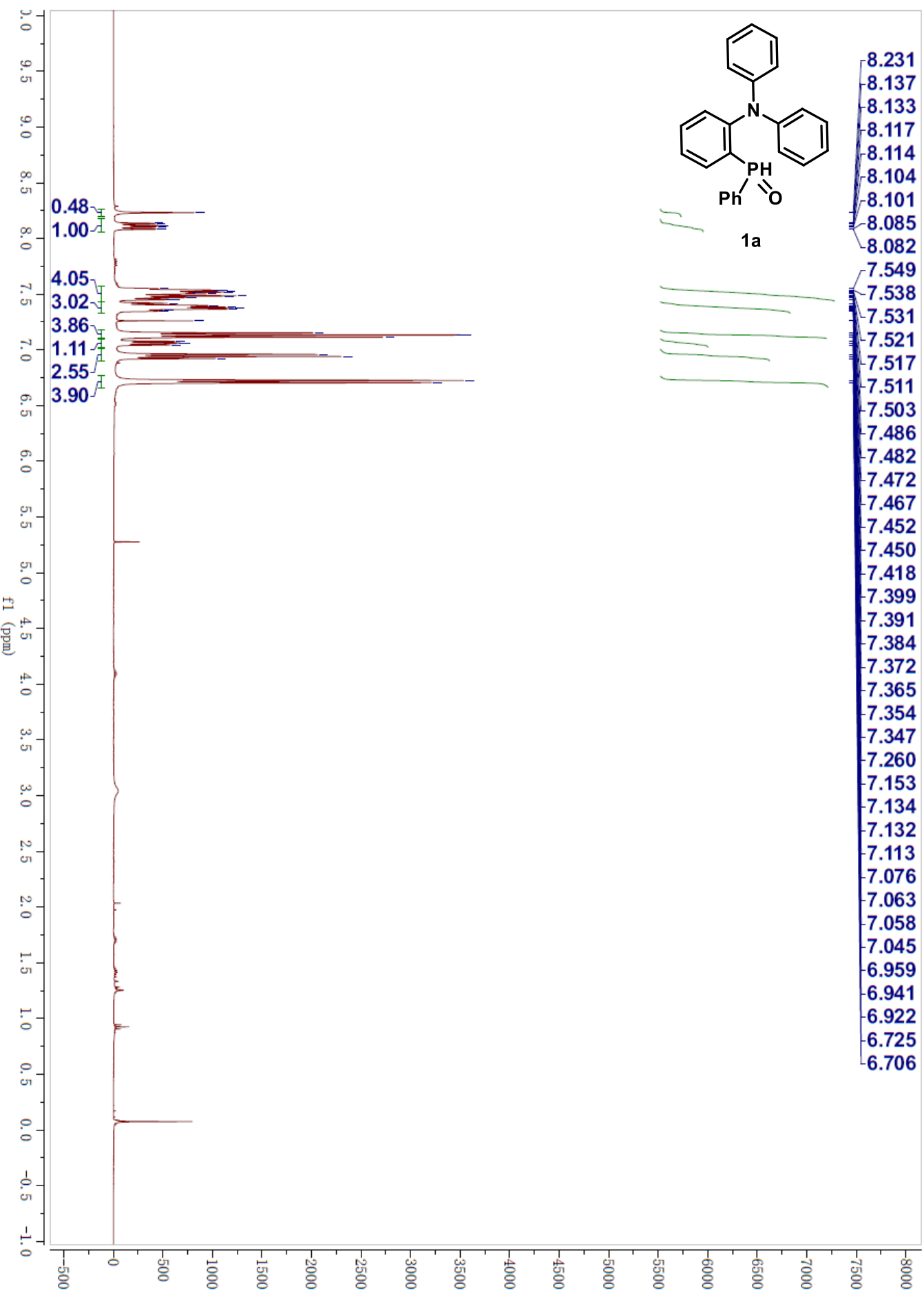




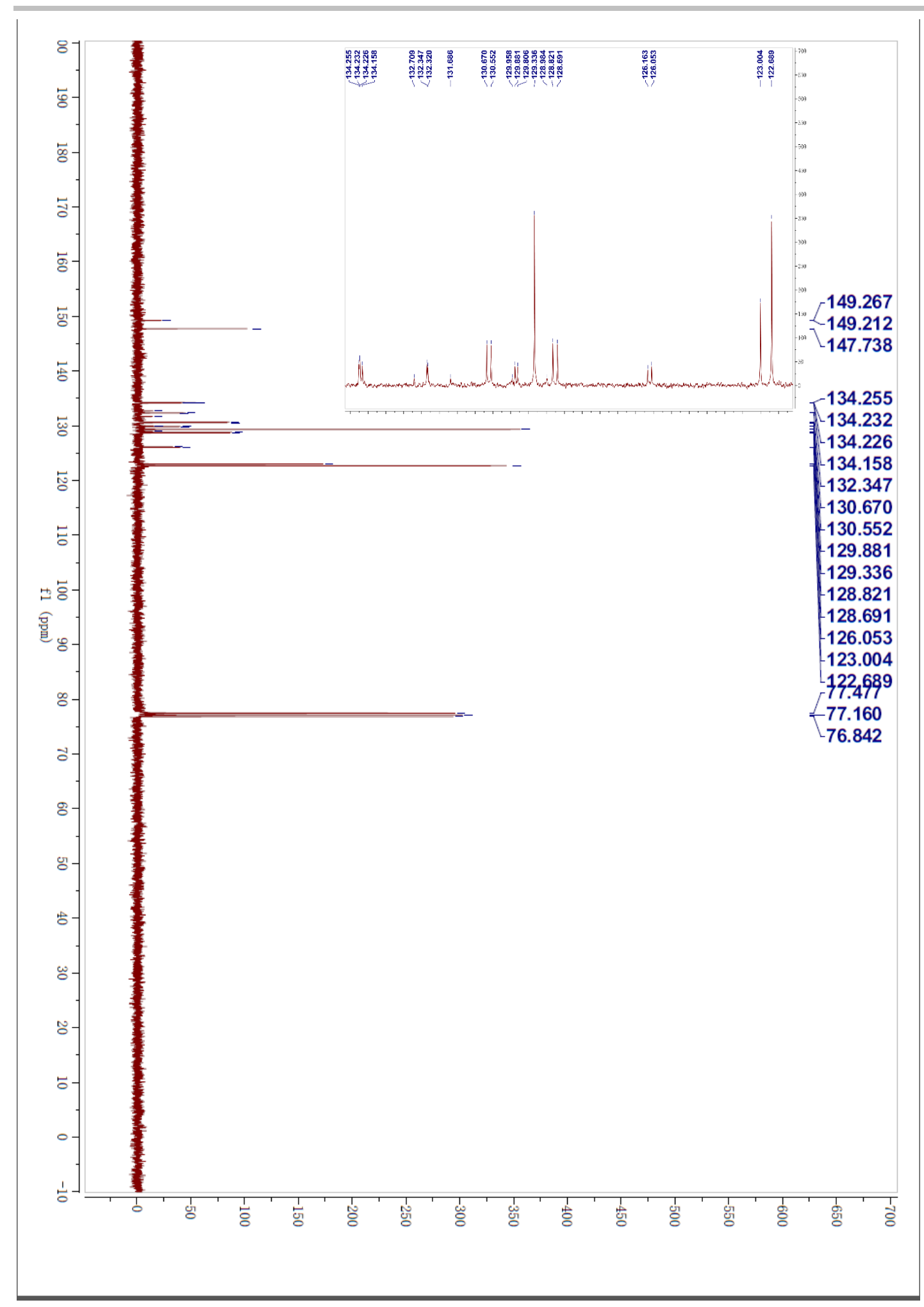<smiles>O=[PH](c1ccccc1)c1ccccc1N(c1ccccc1)c1ccccc1</smiles>

1a 


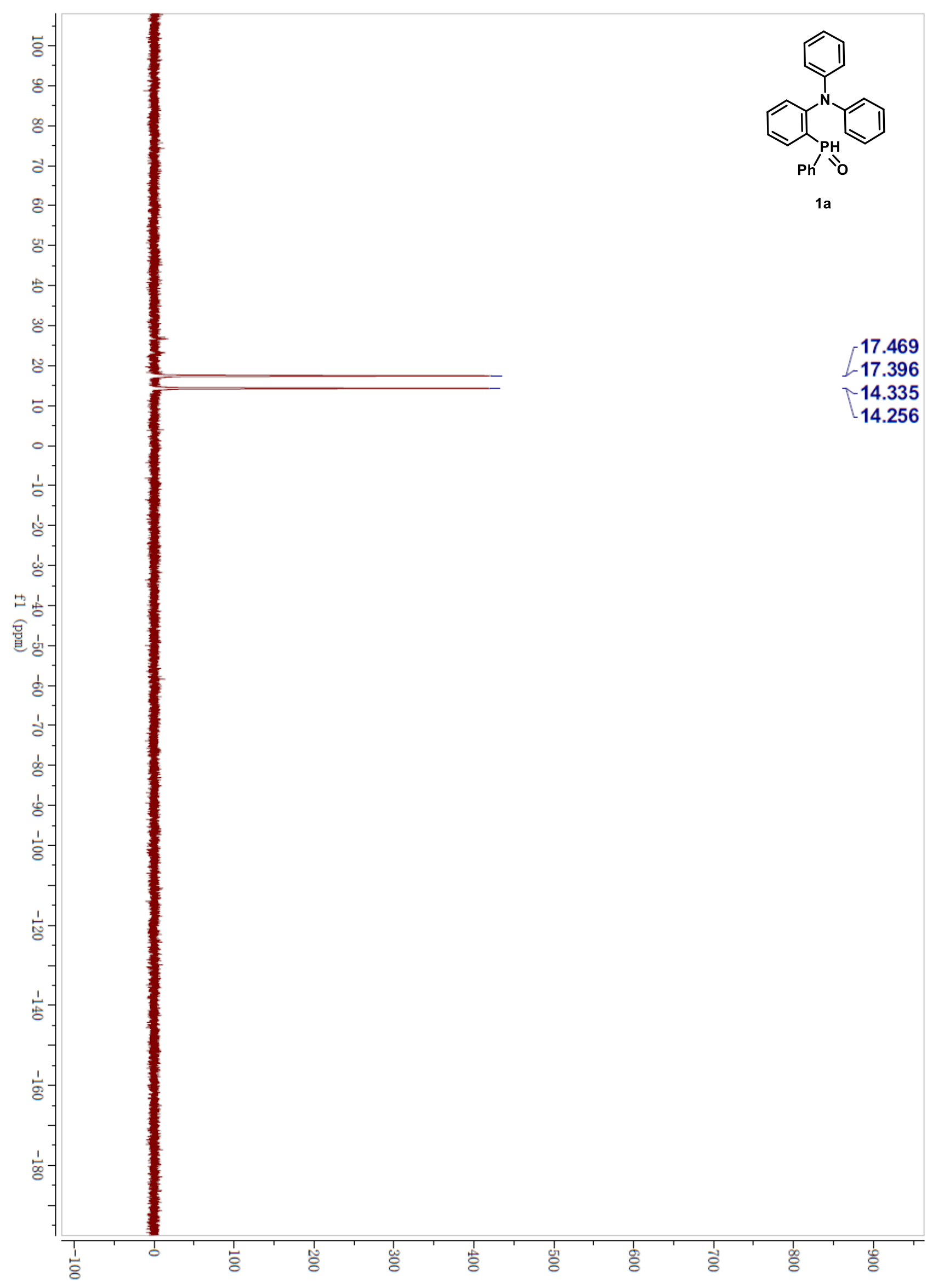




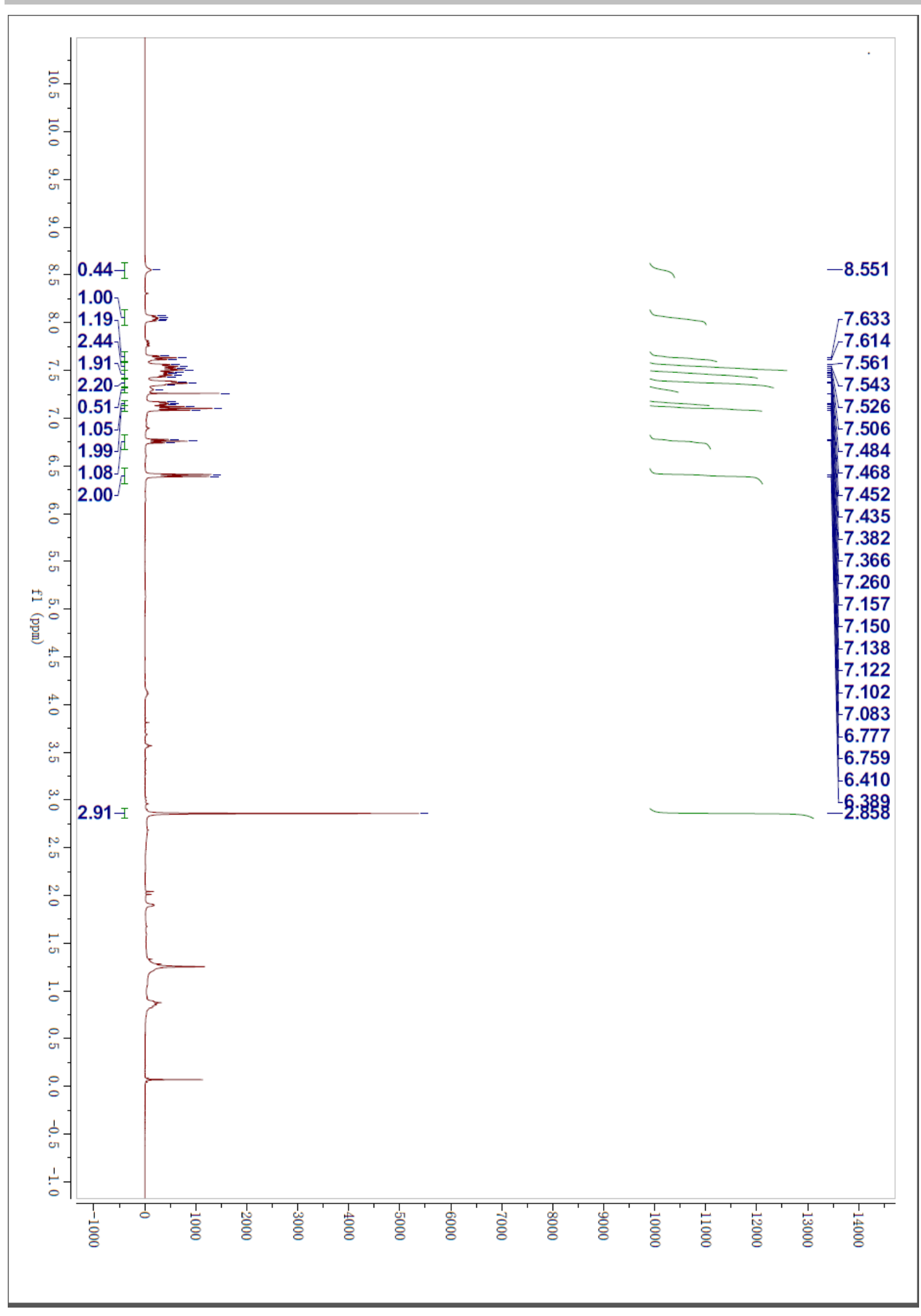

1b 


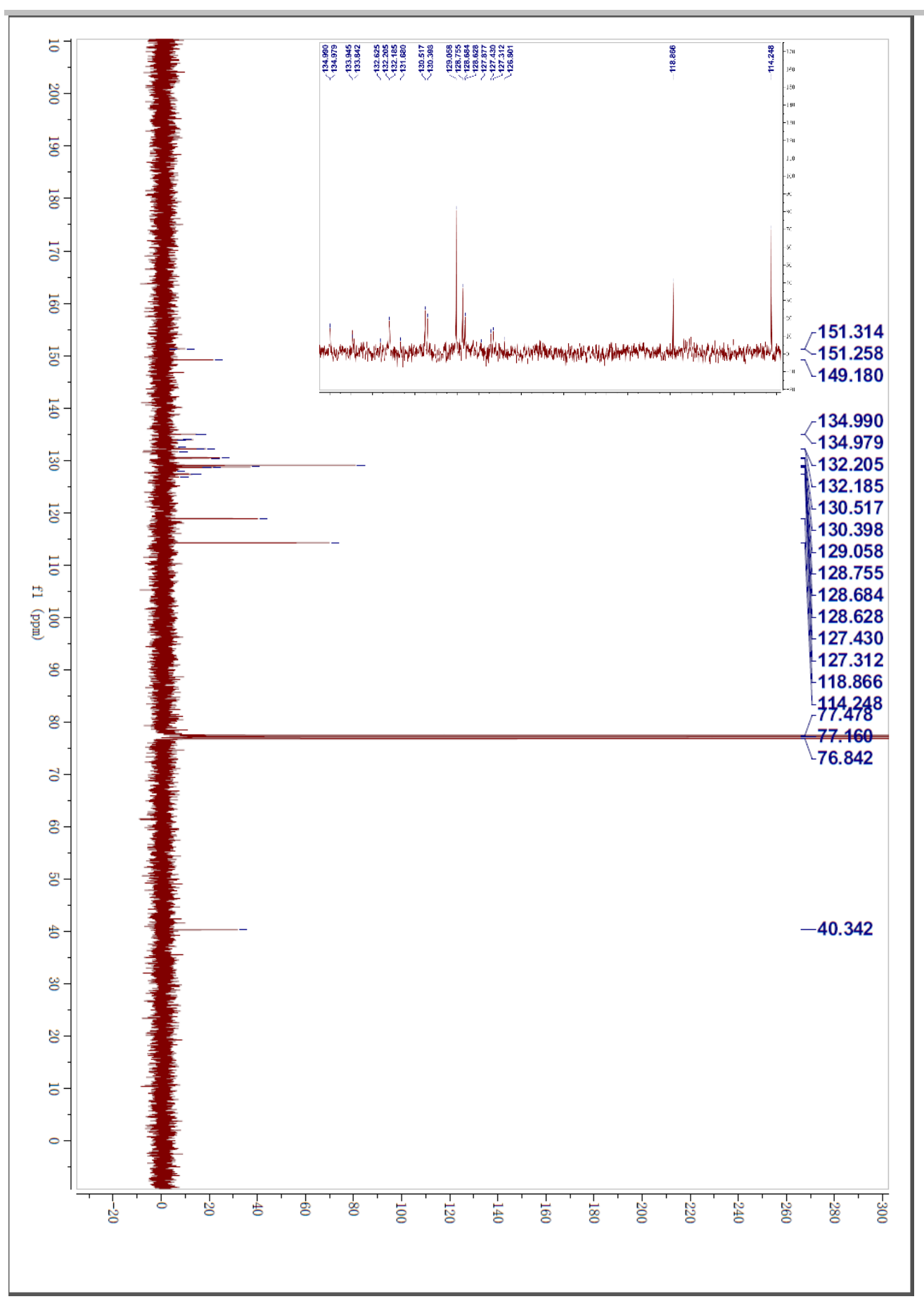

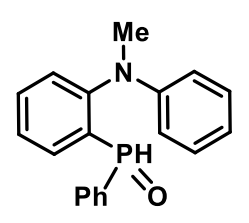

$1 b$ 


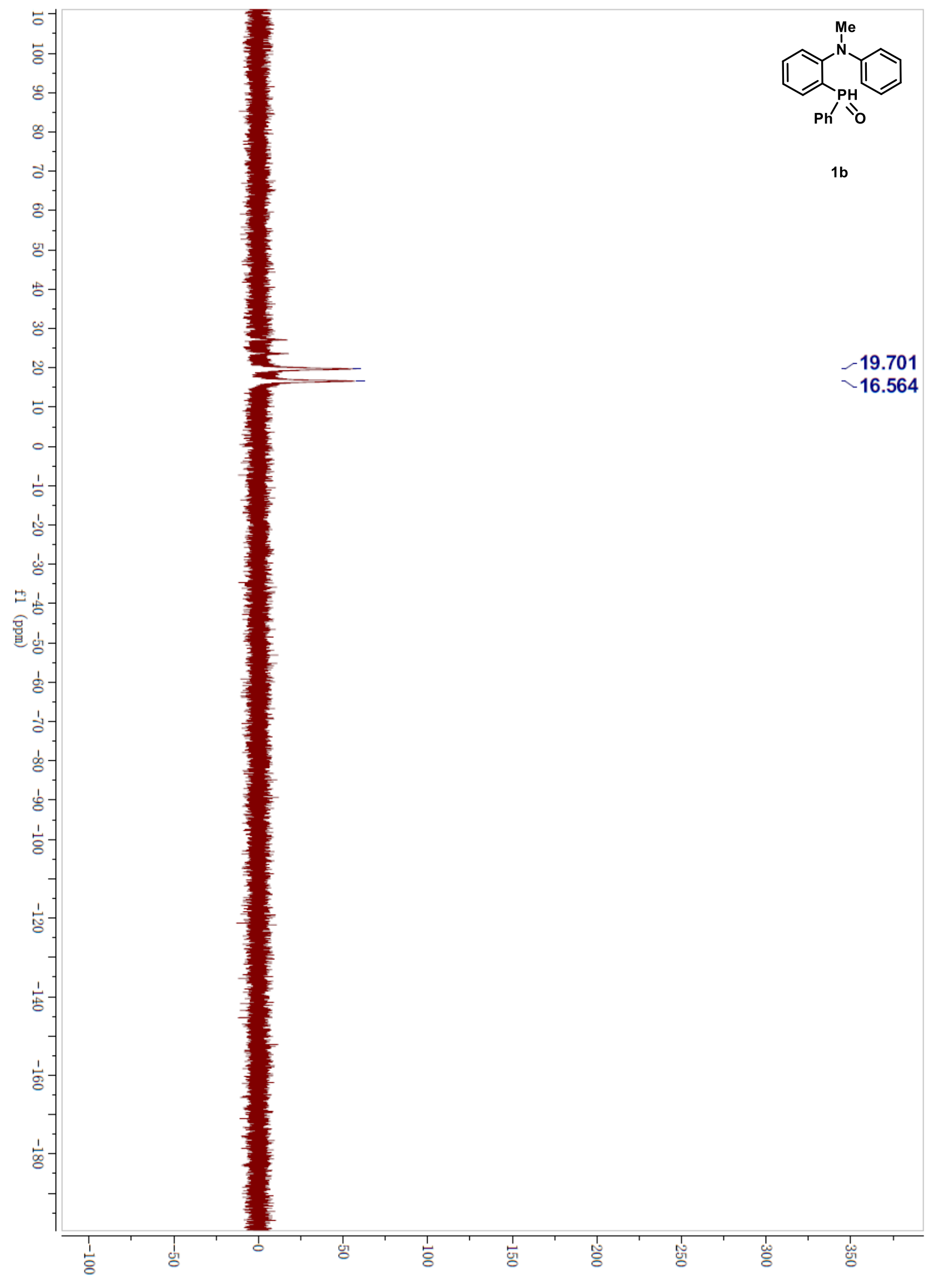




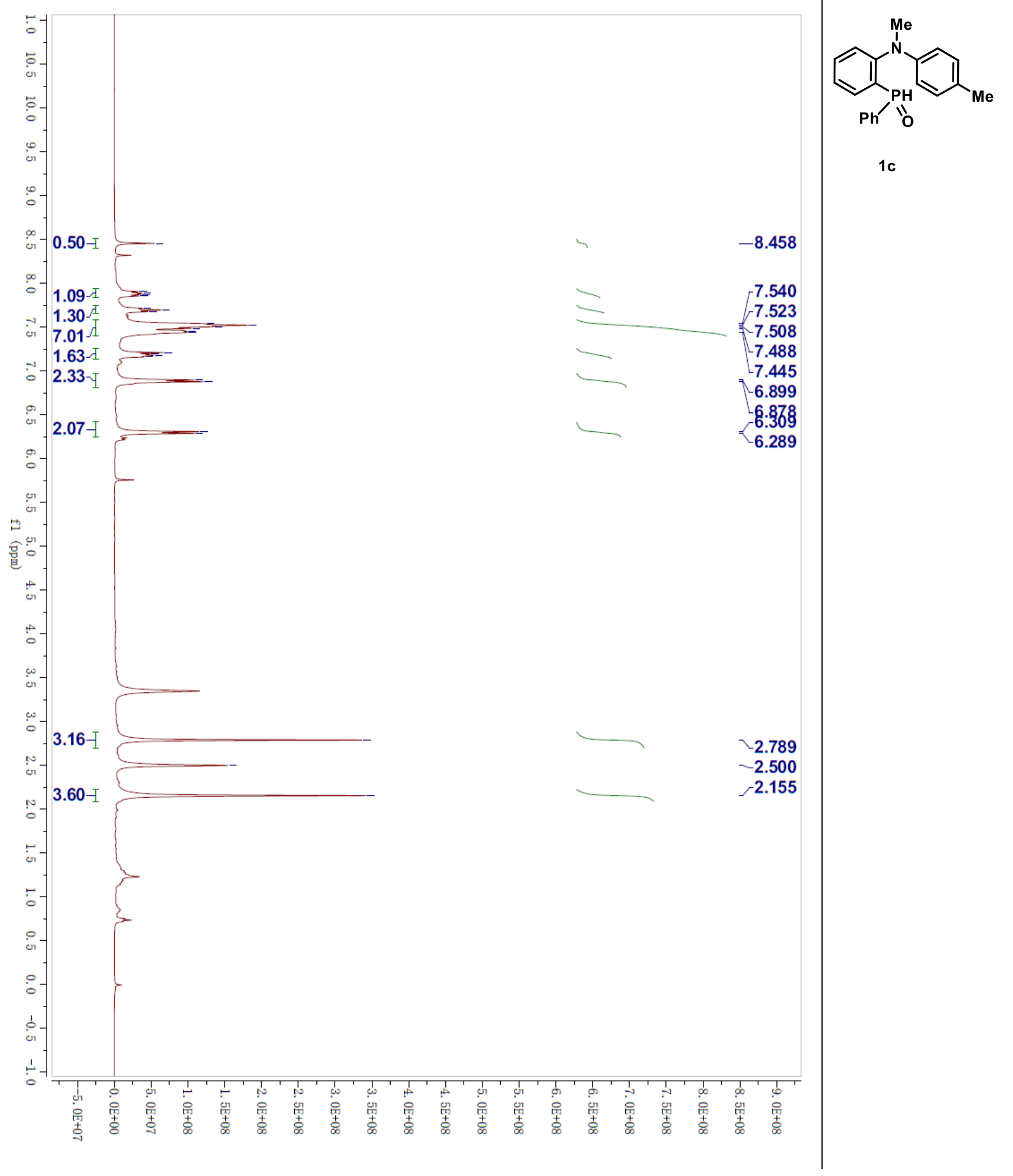




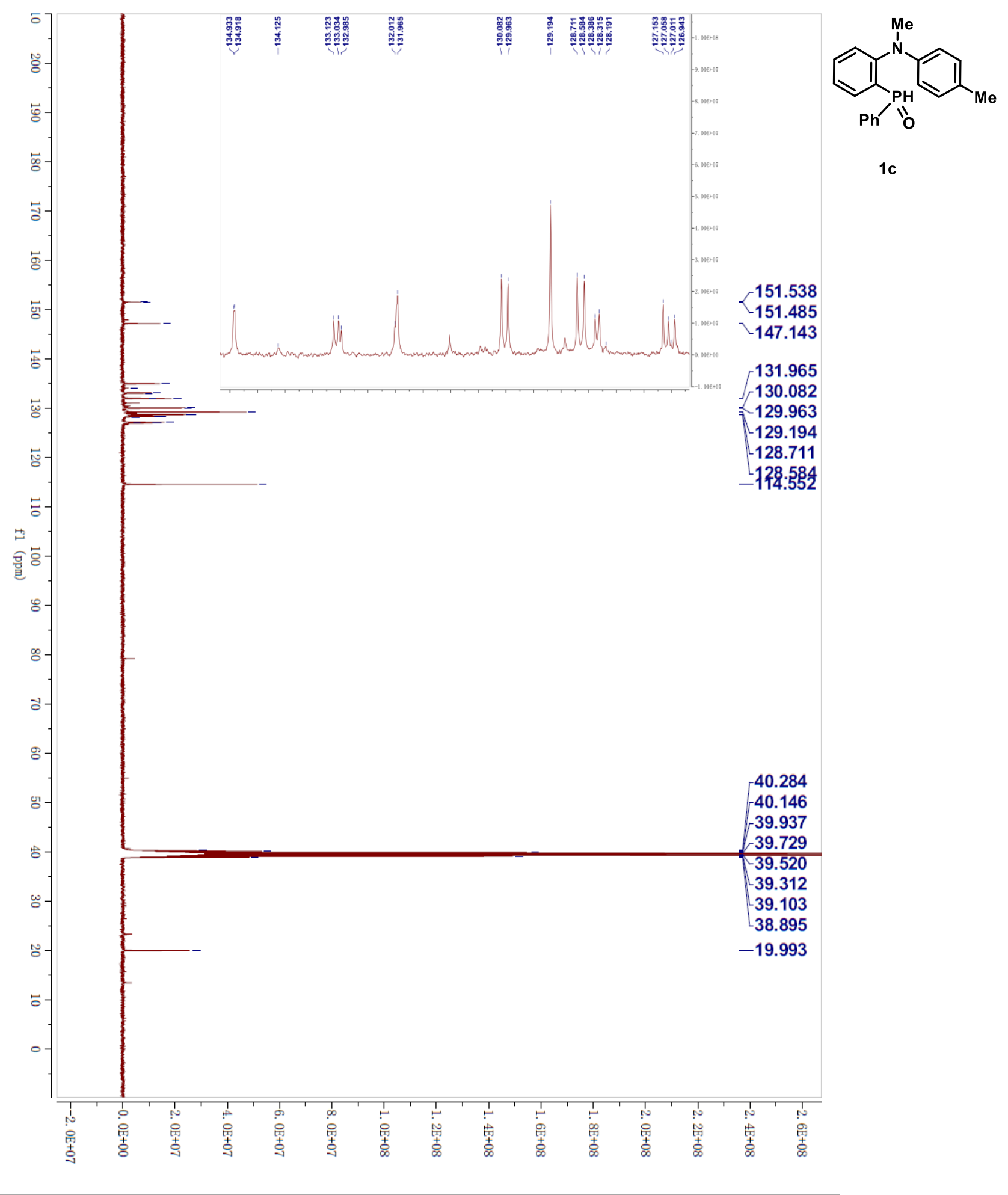




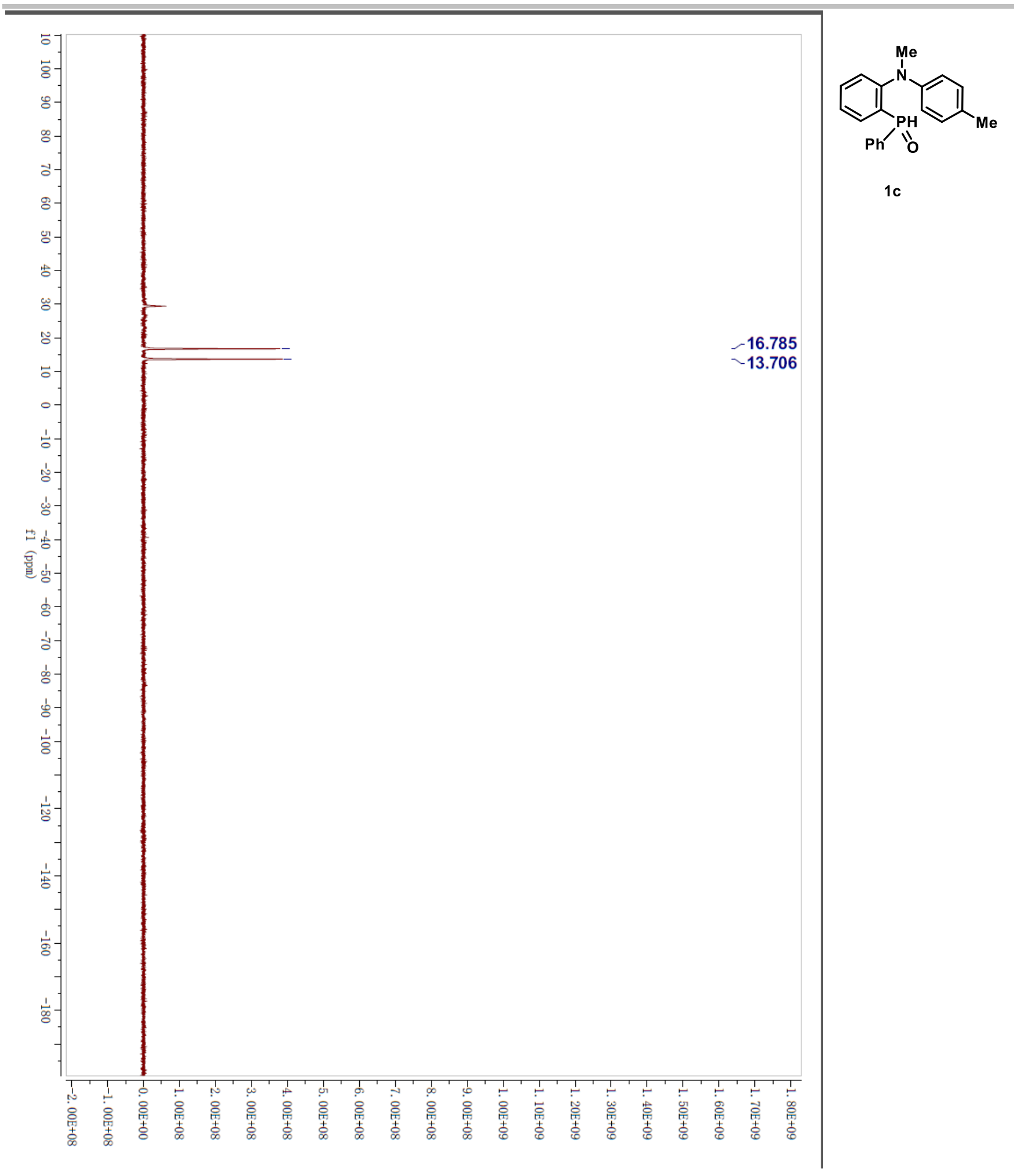




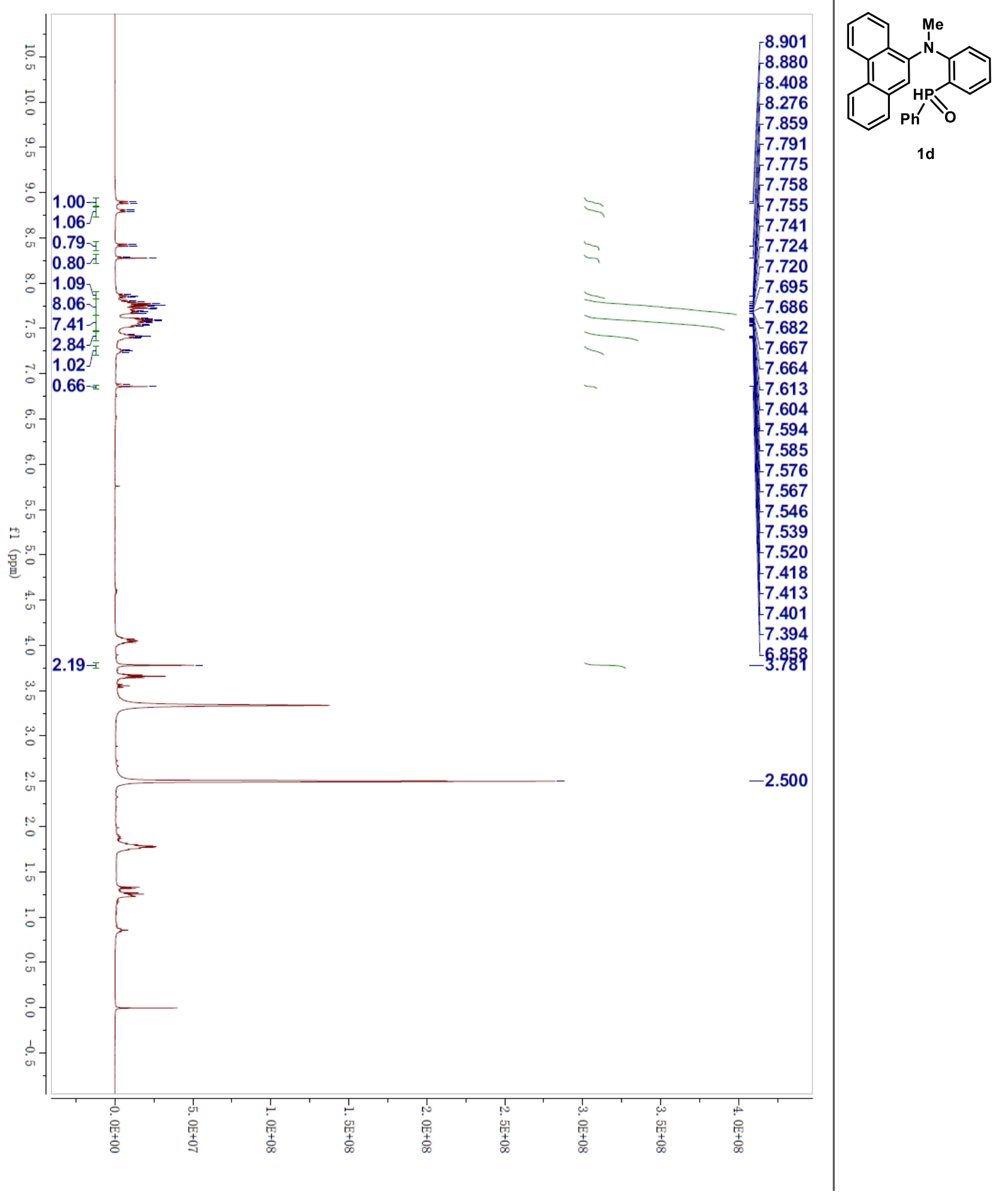




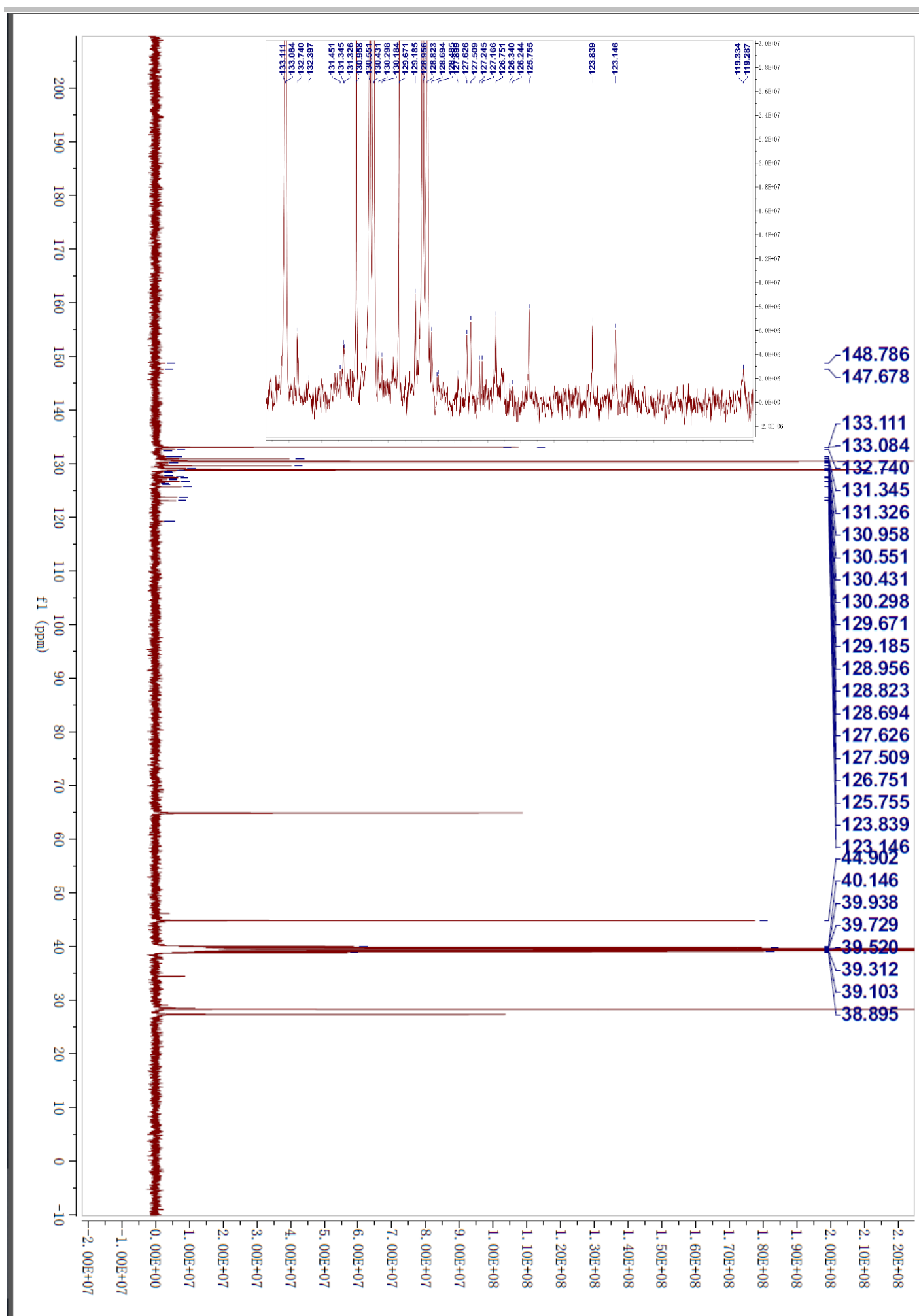




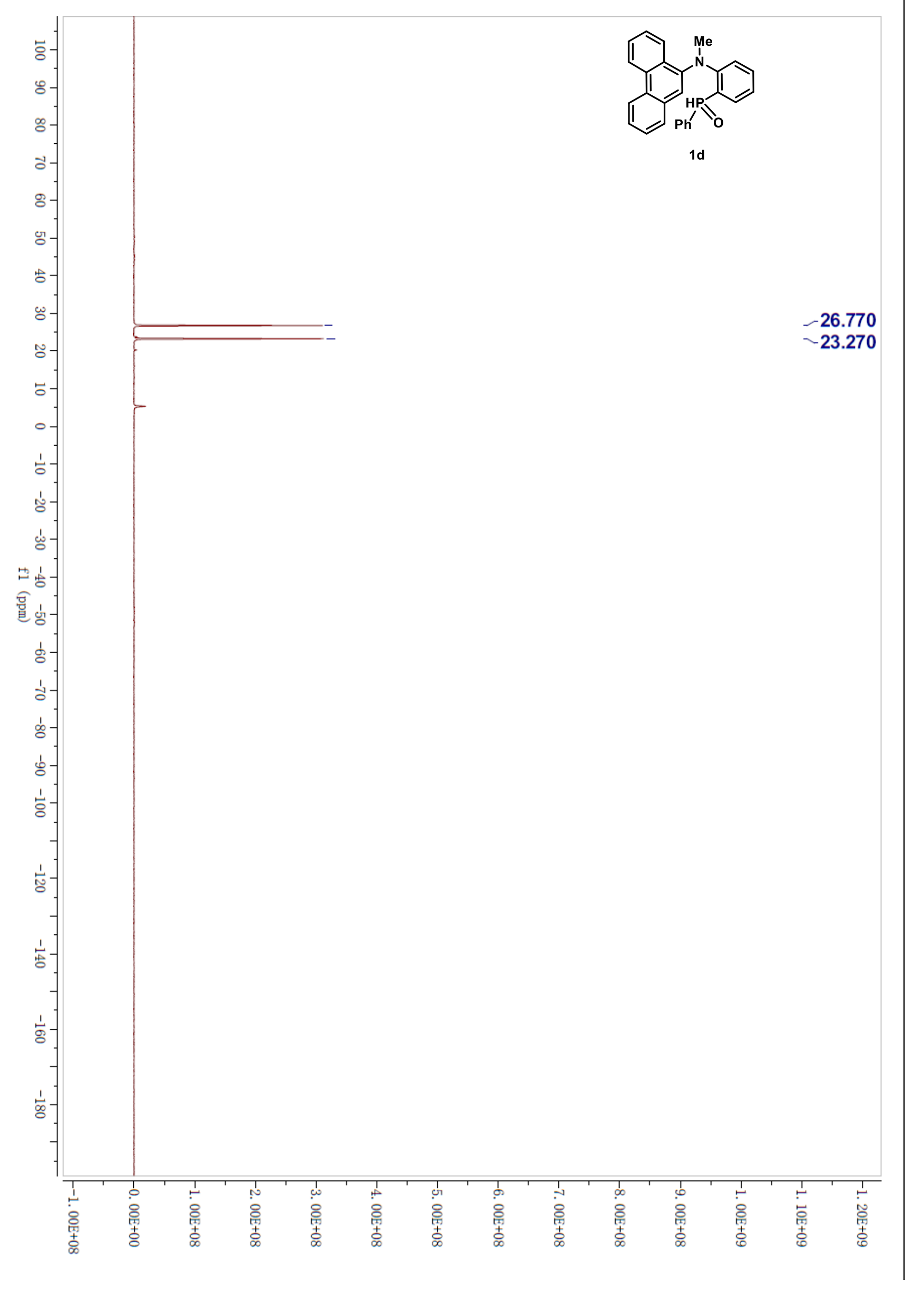




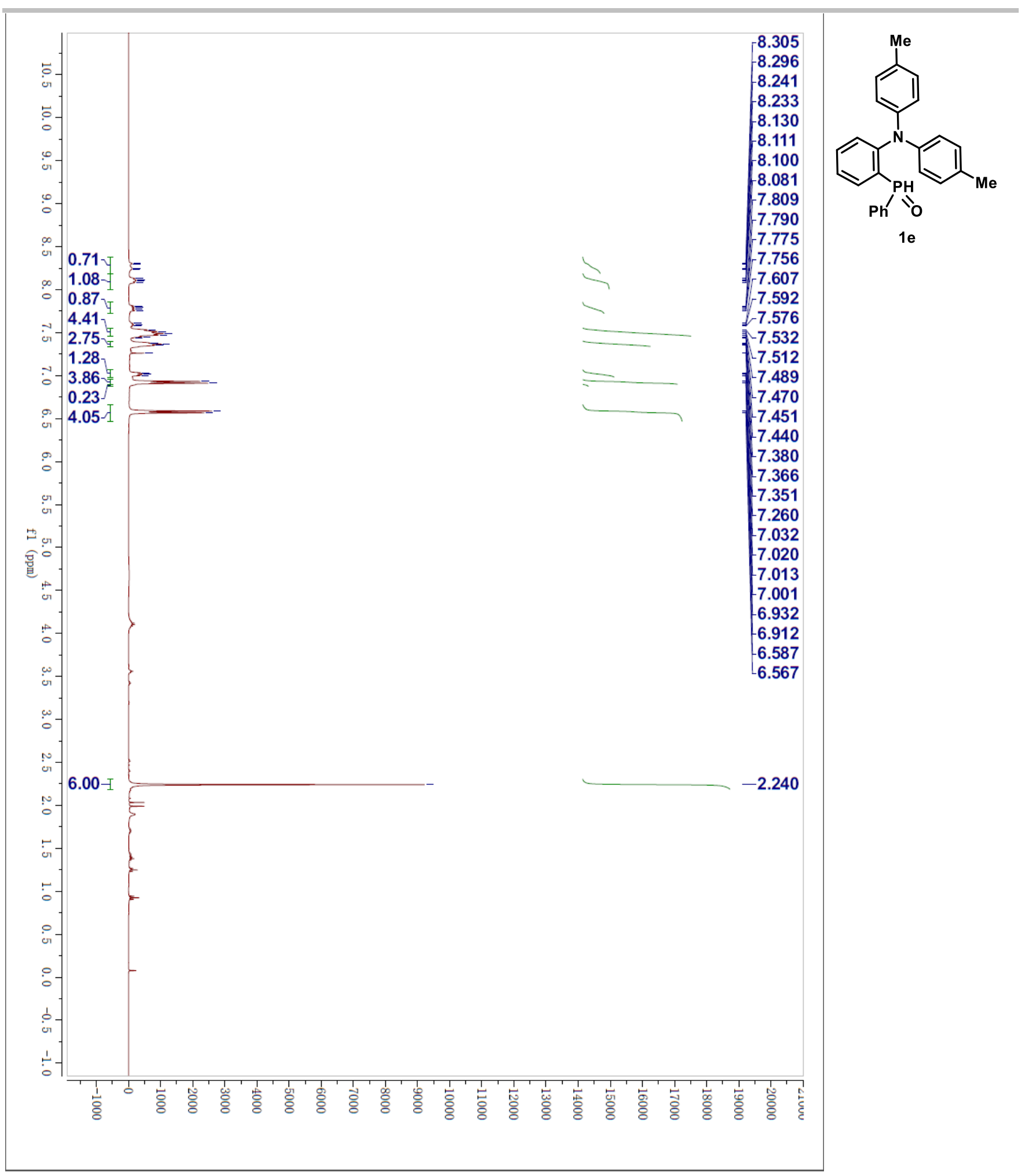




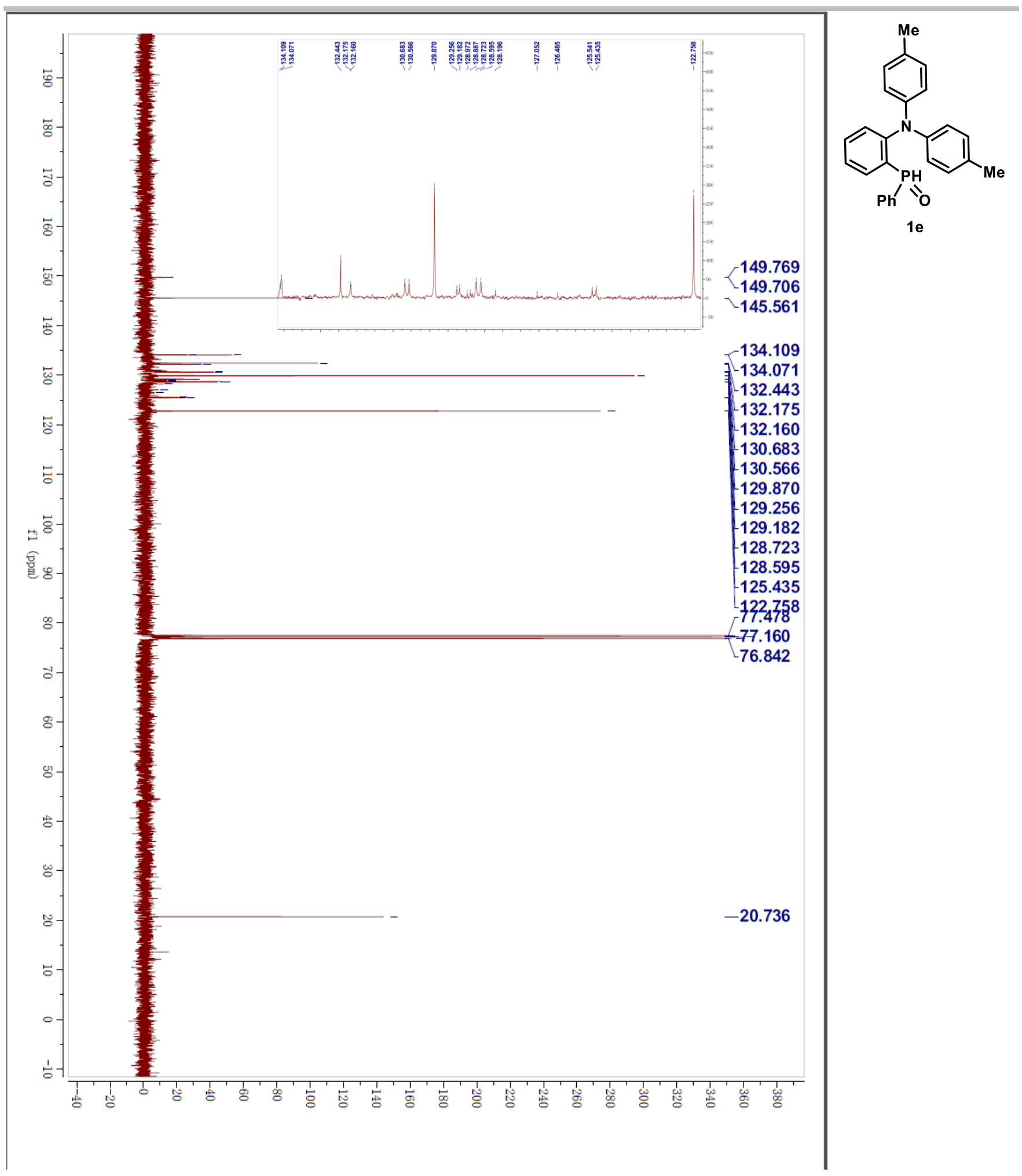




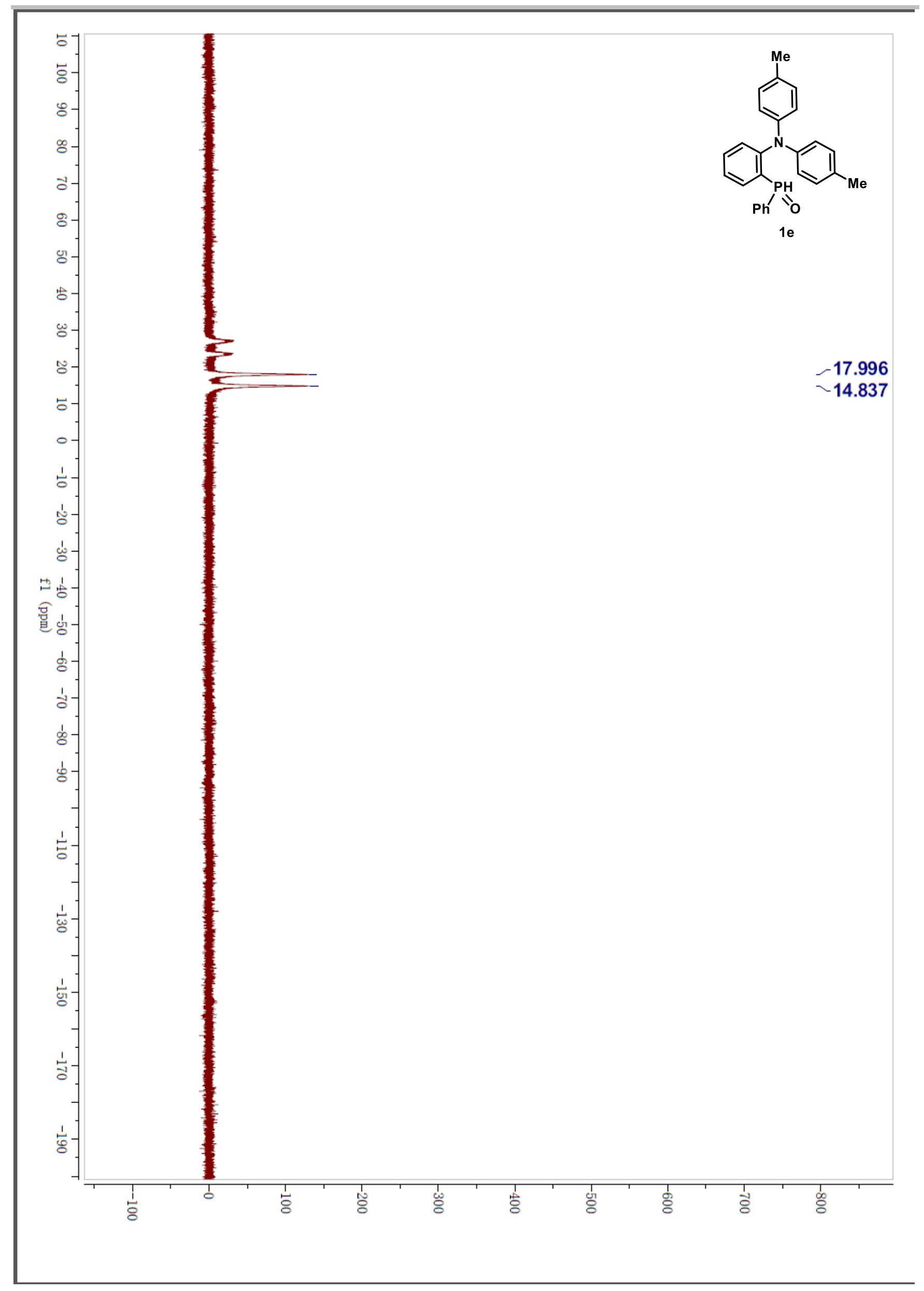




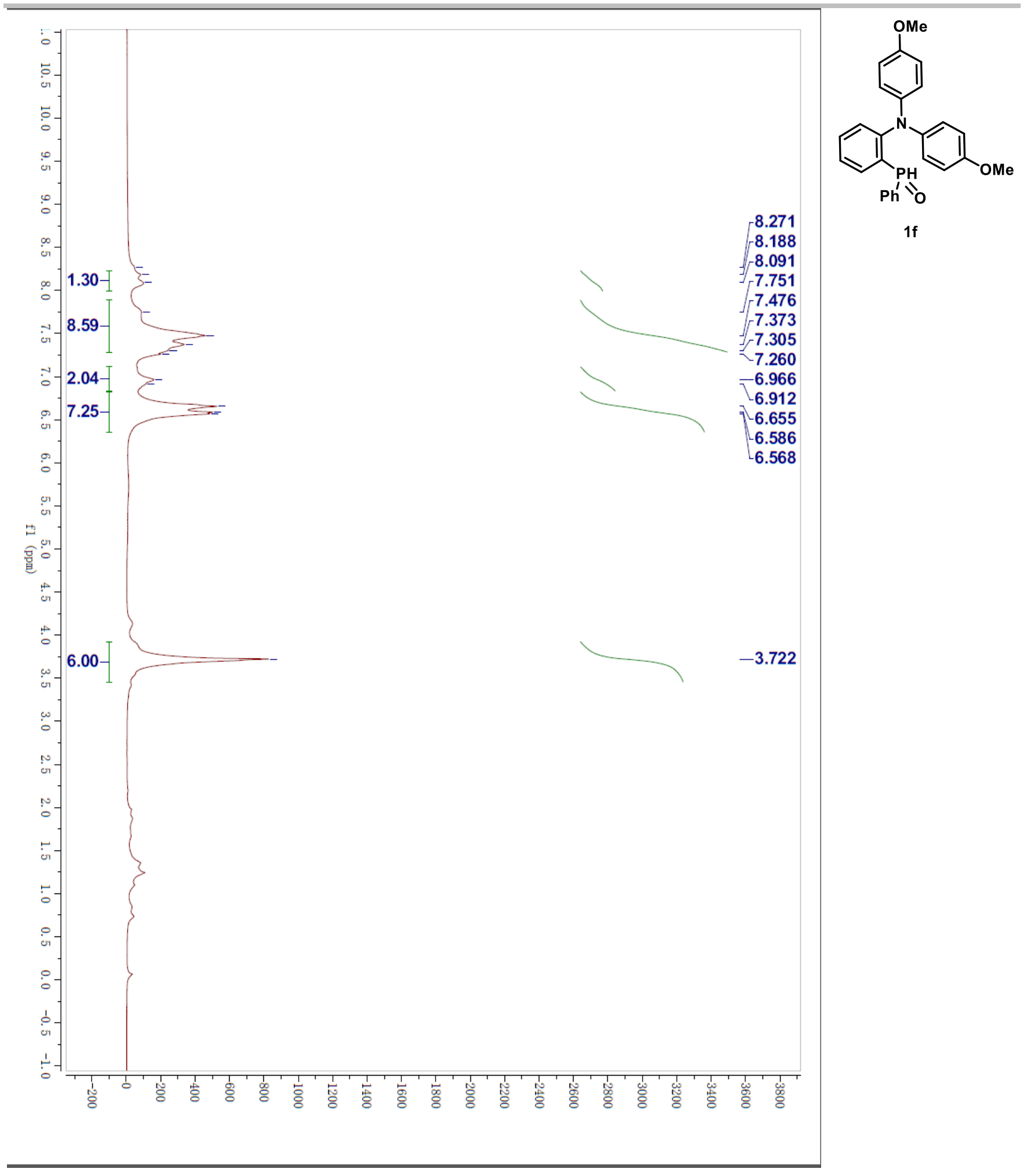




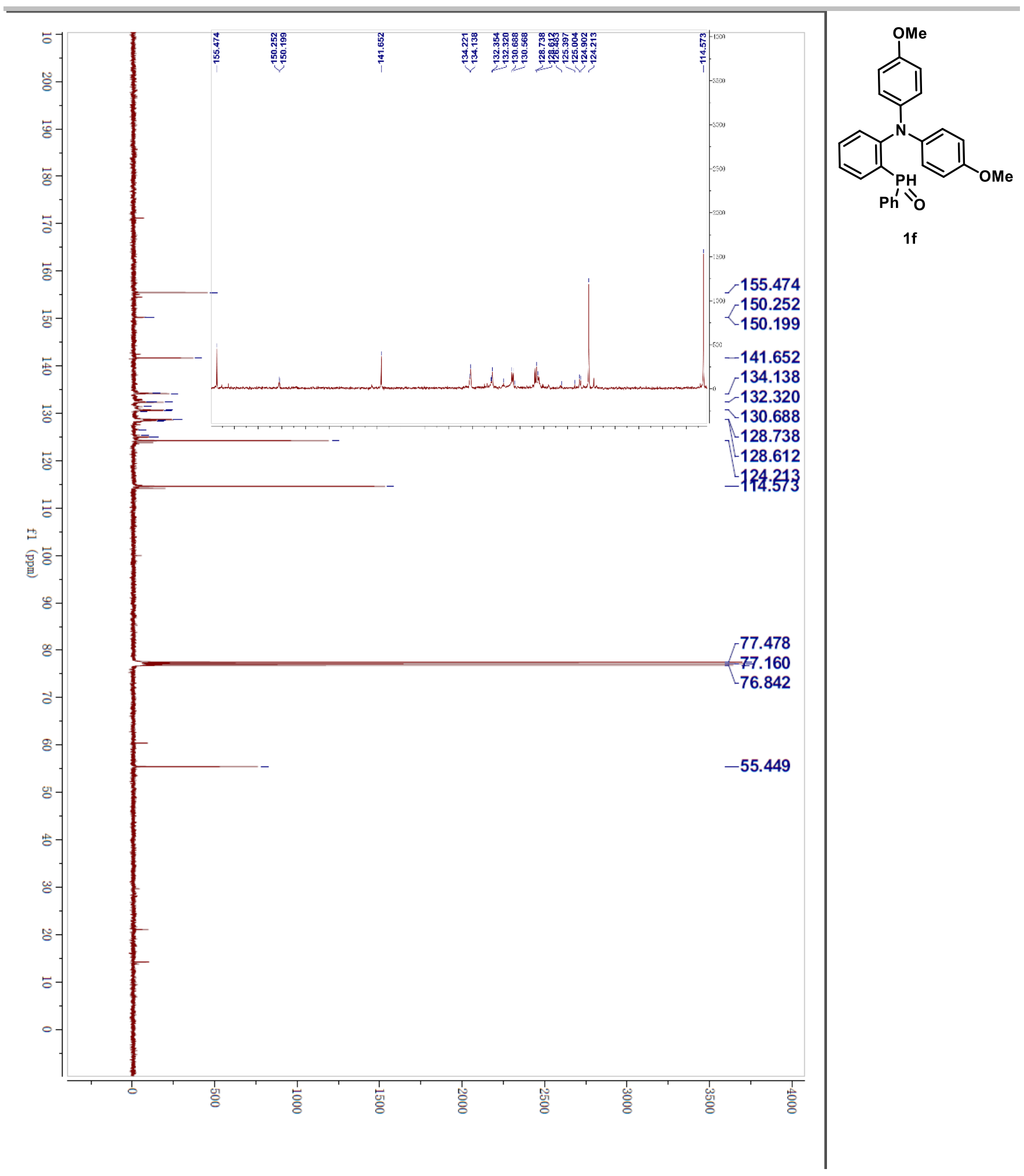




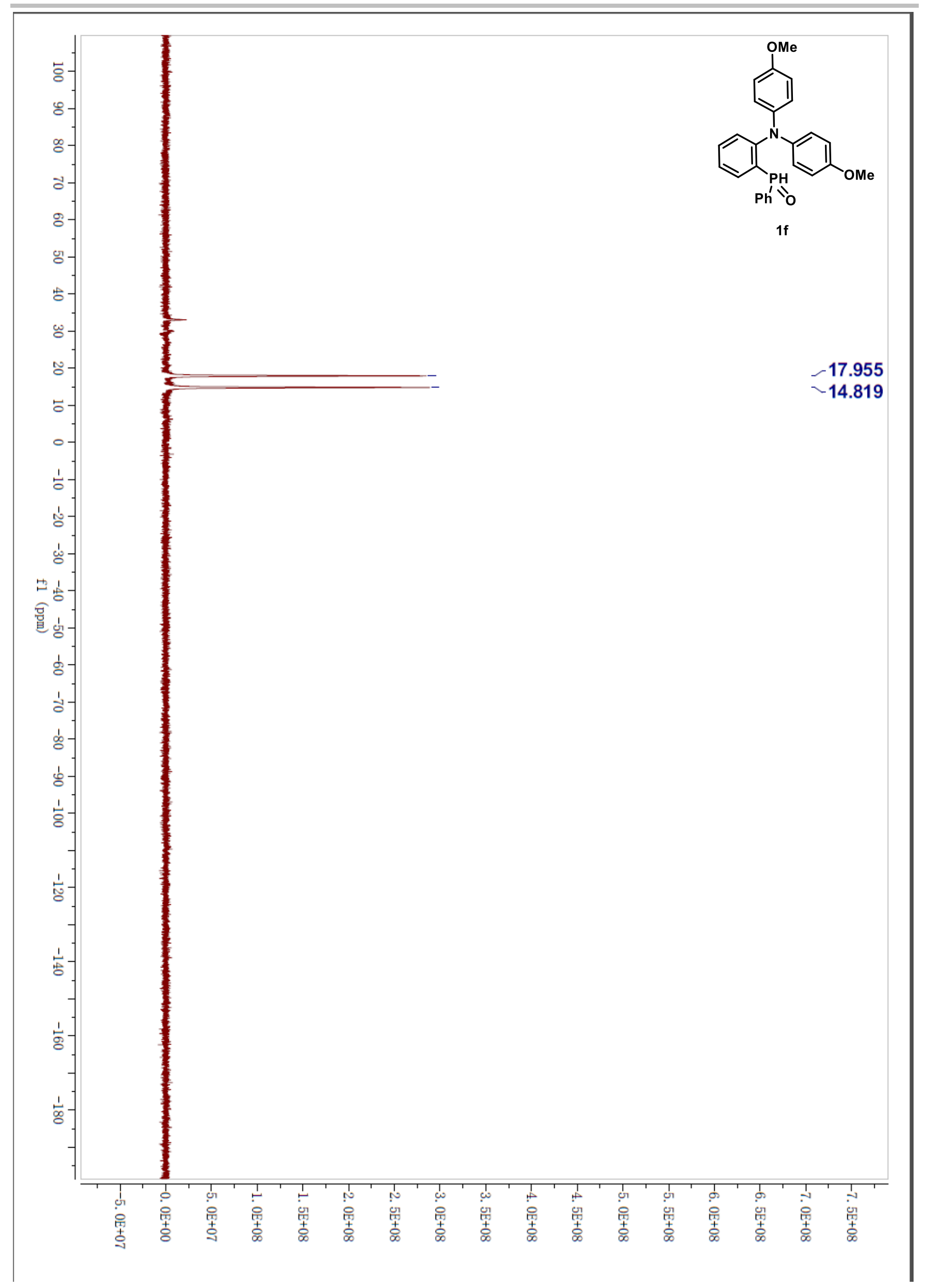




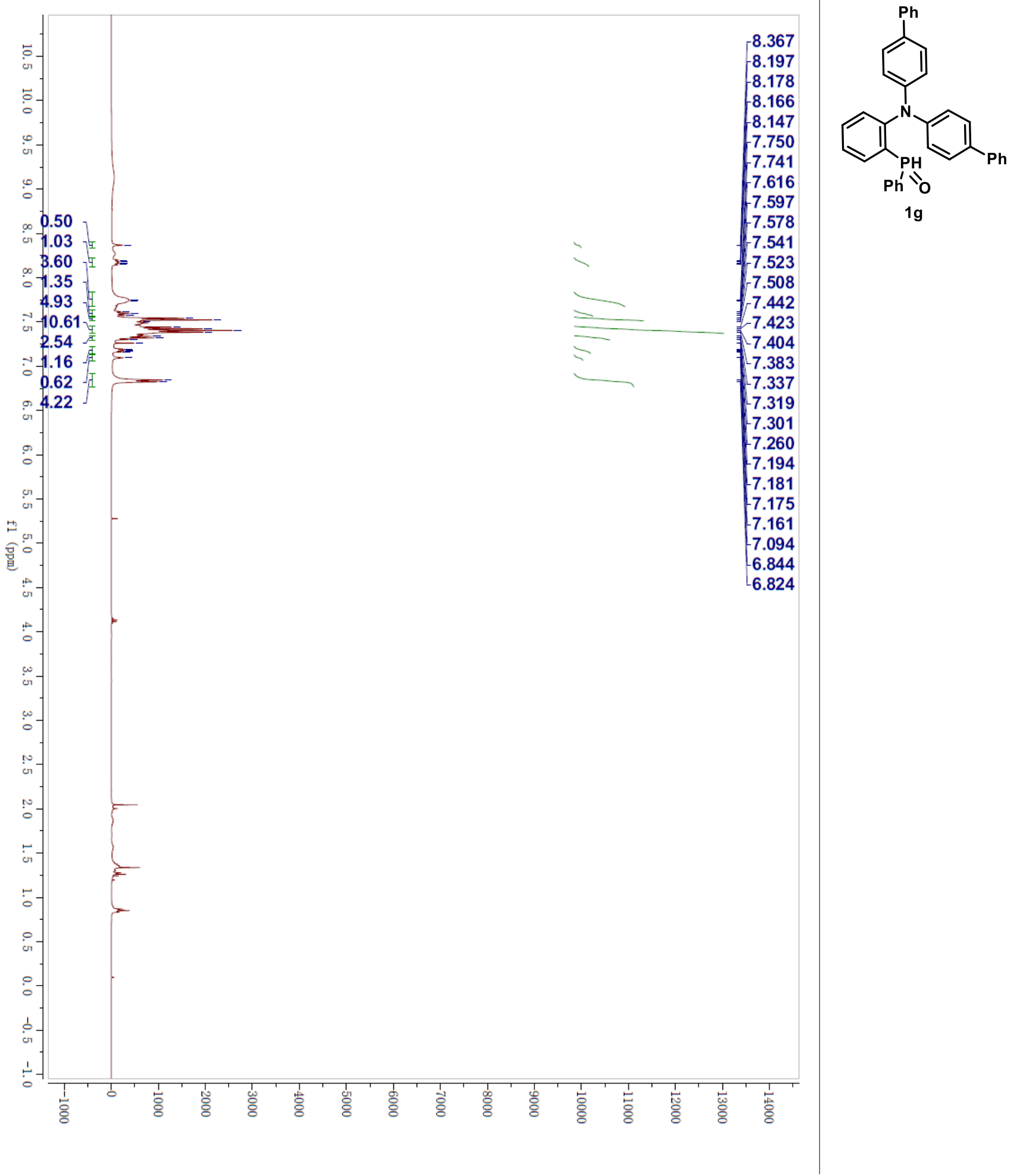




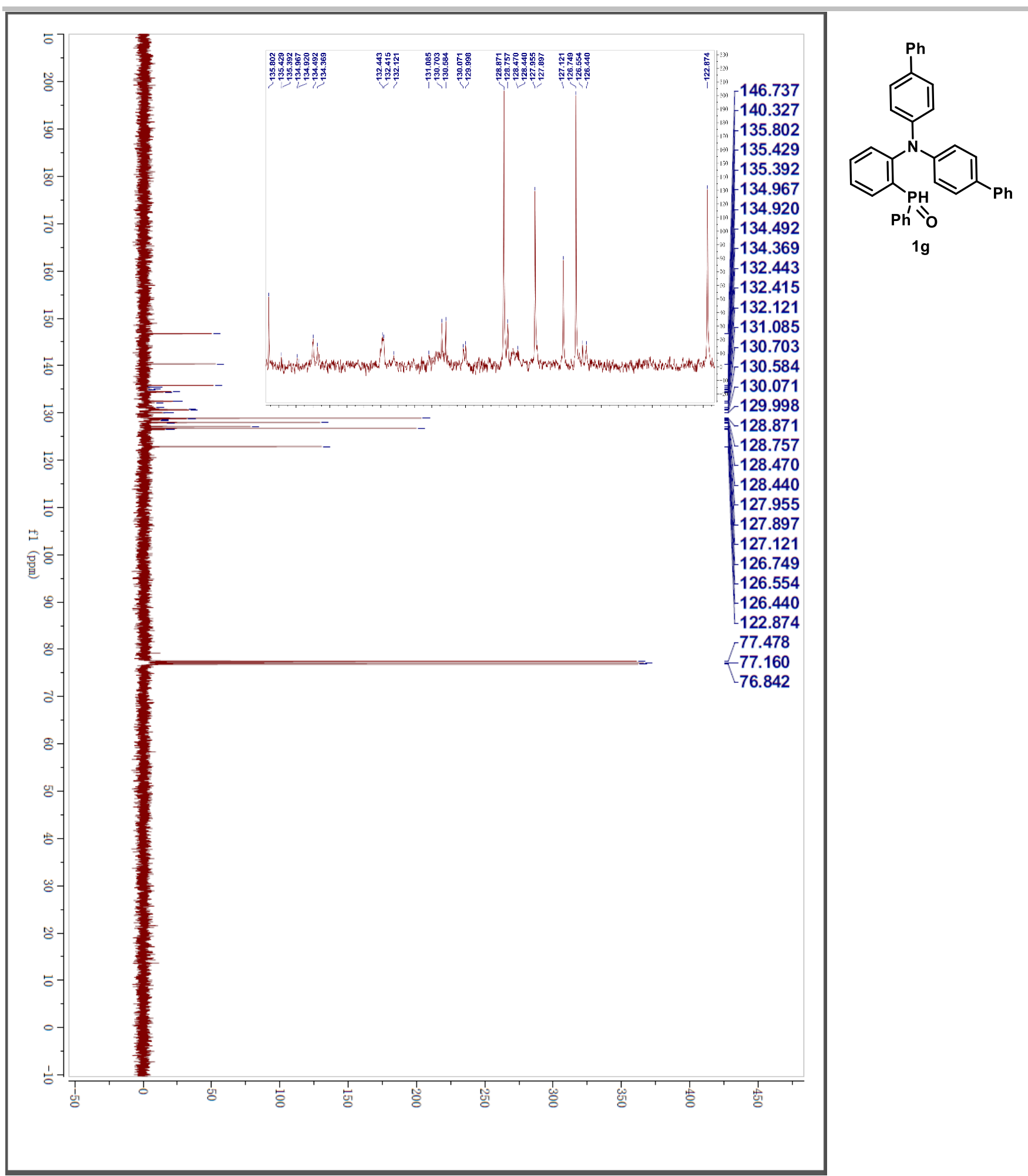




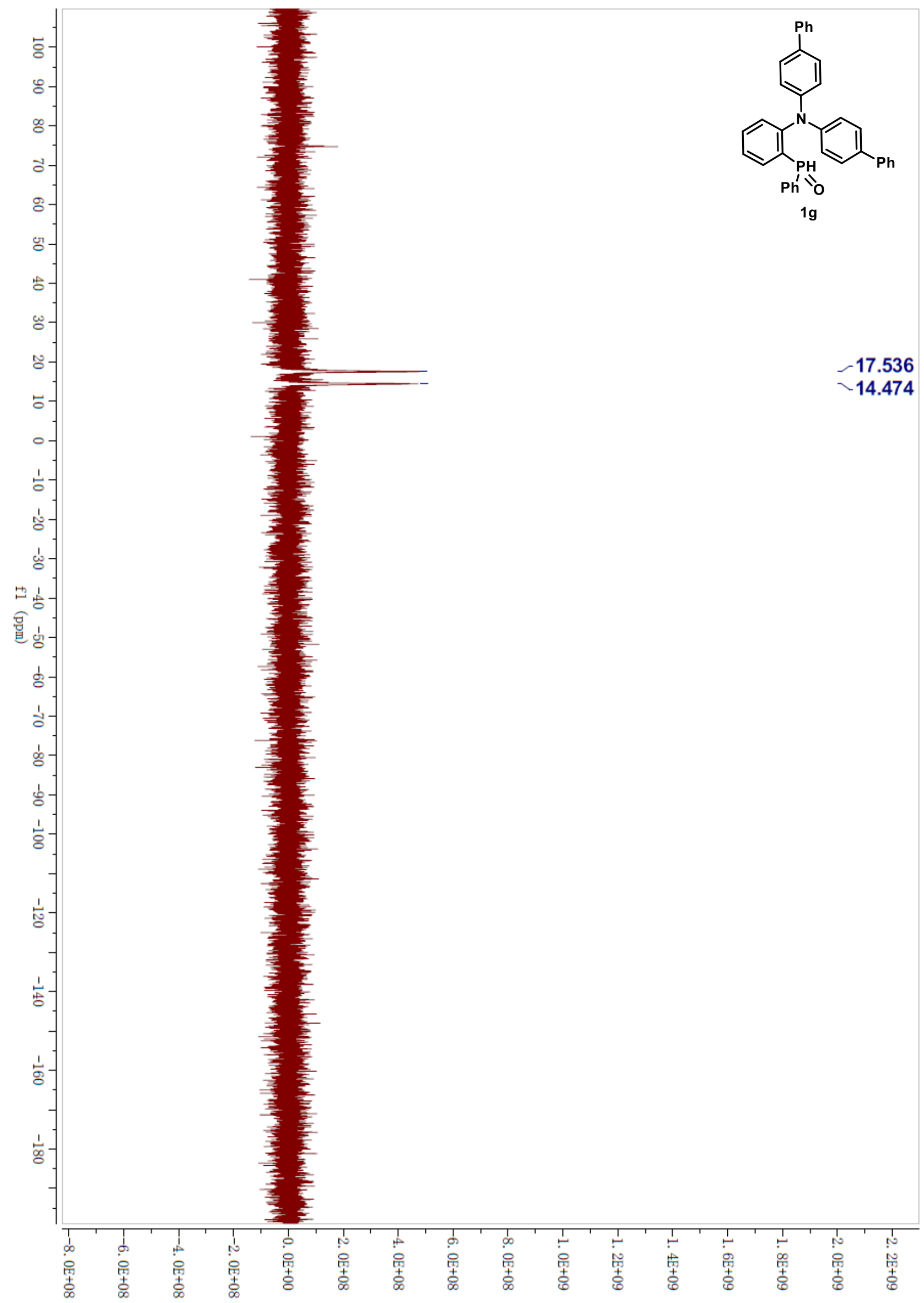




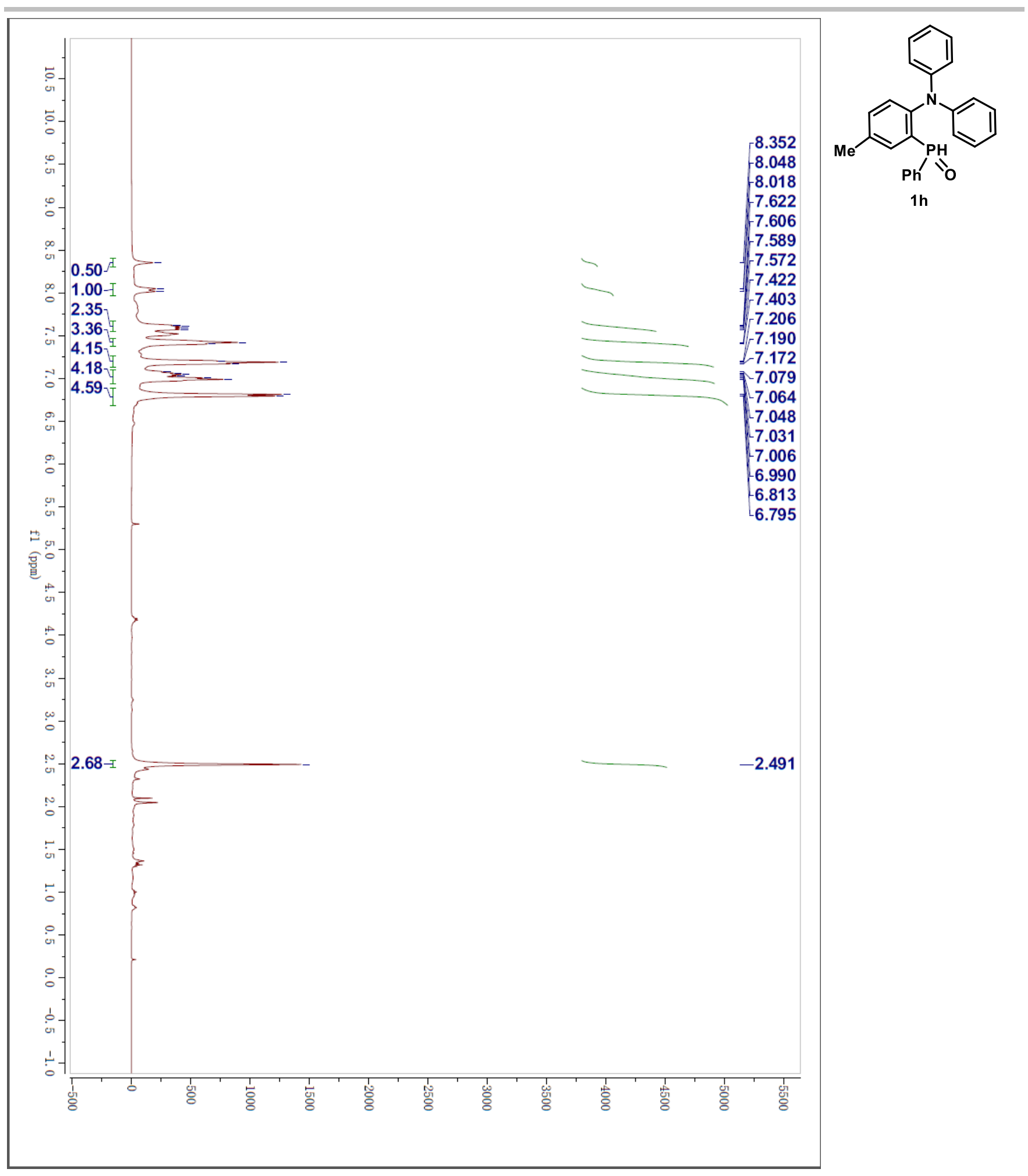




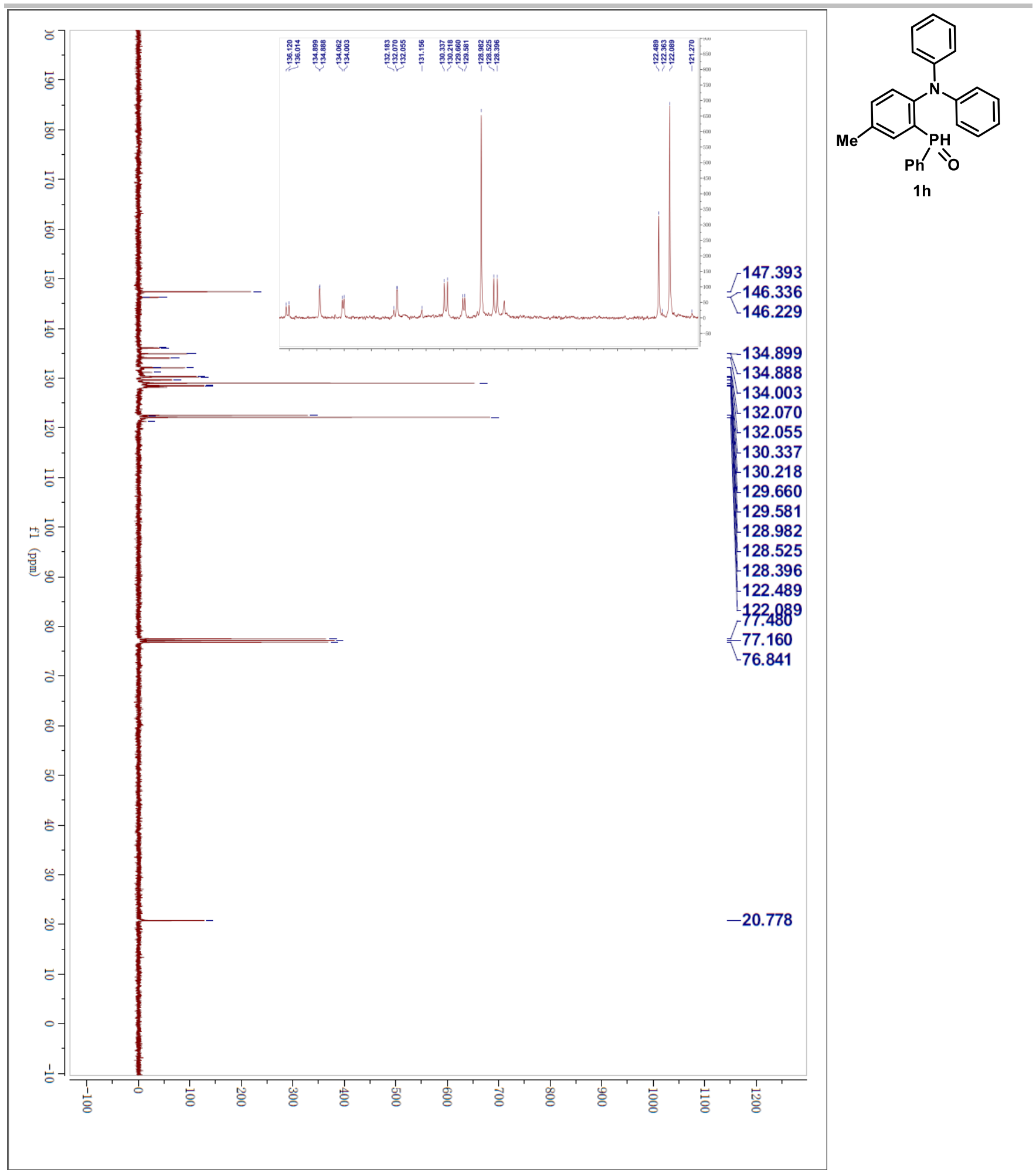




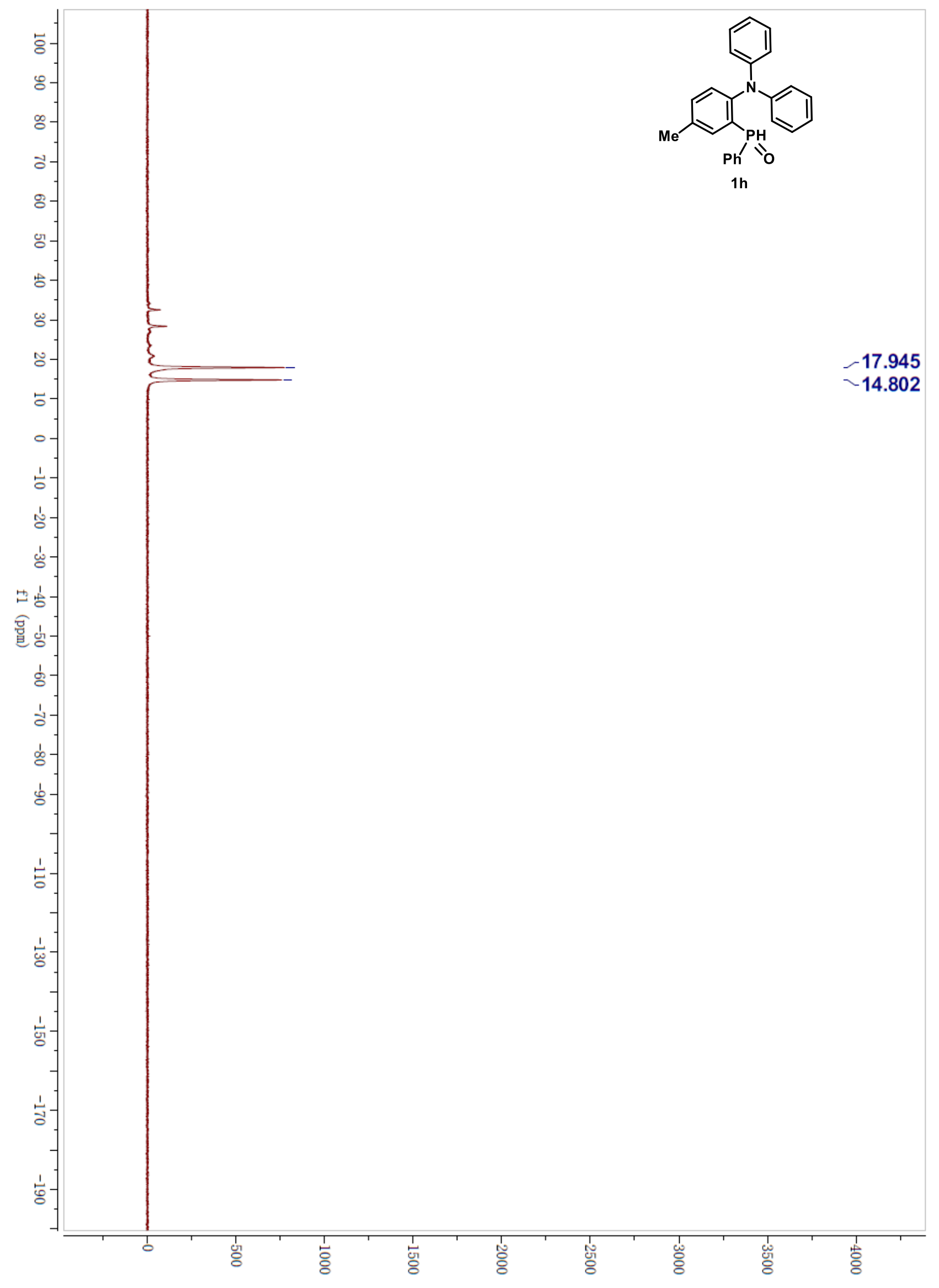




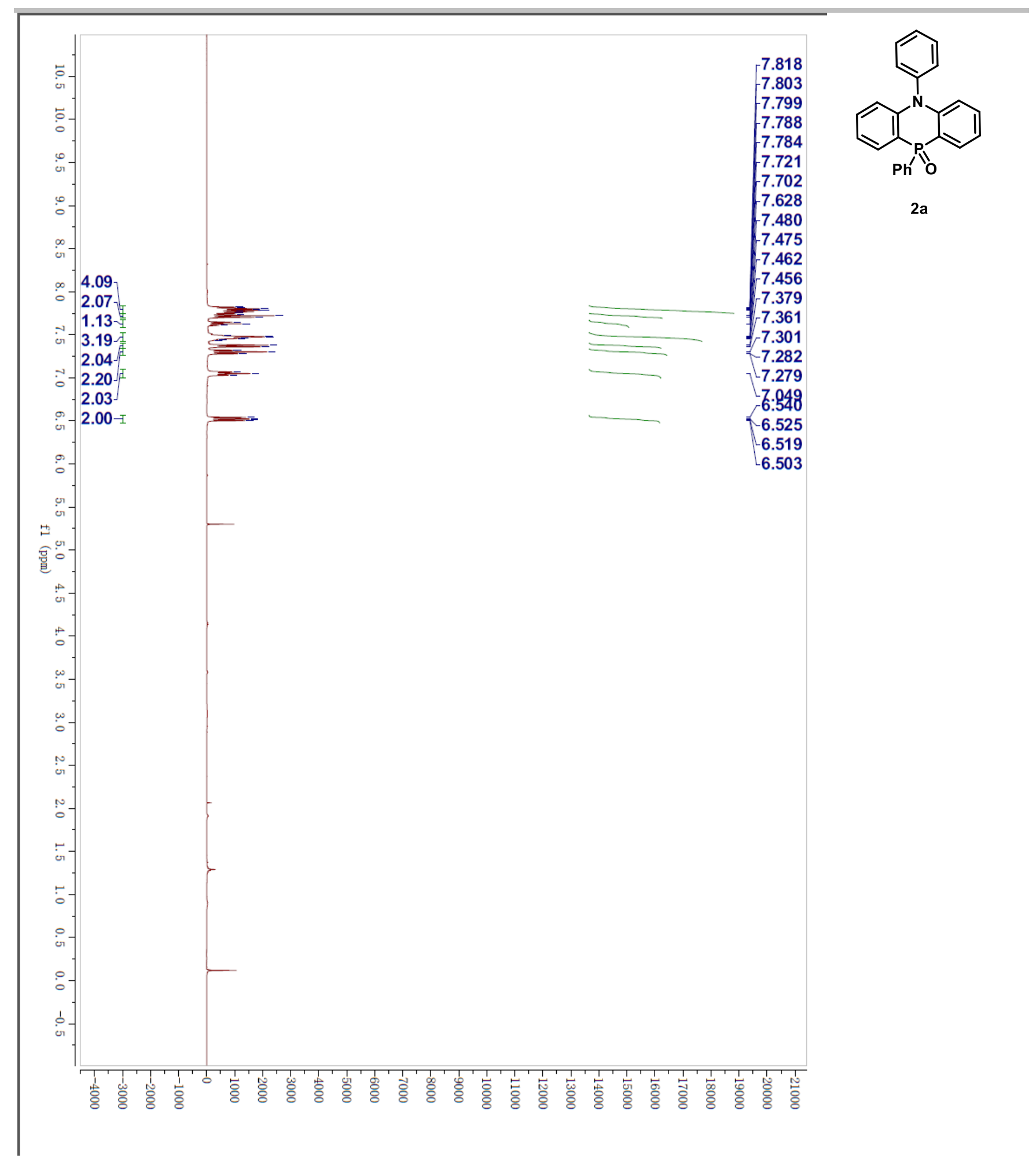




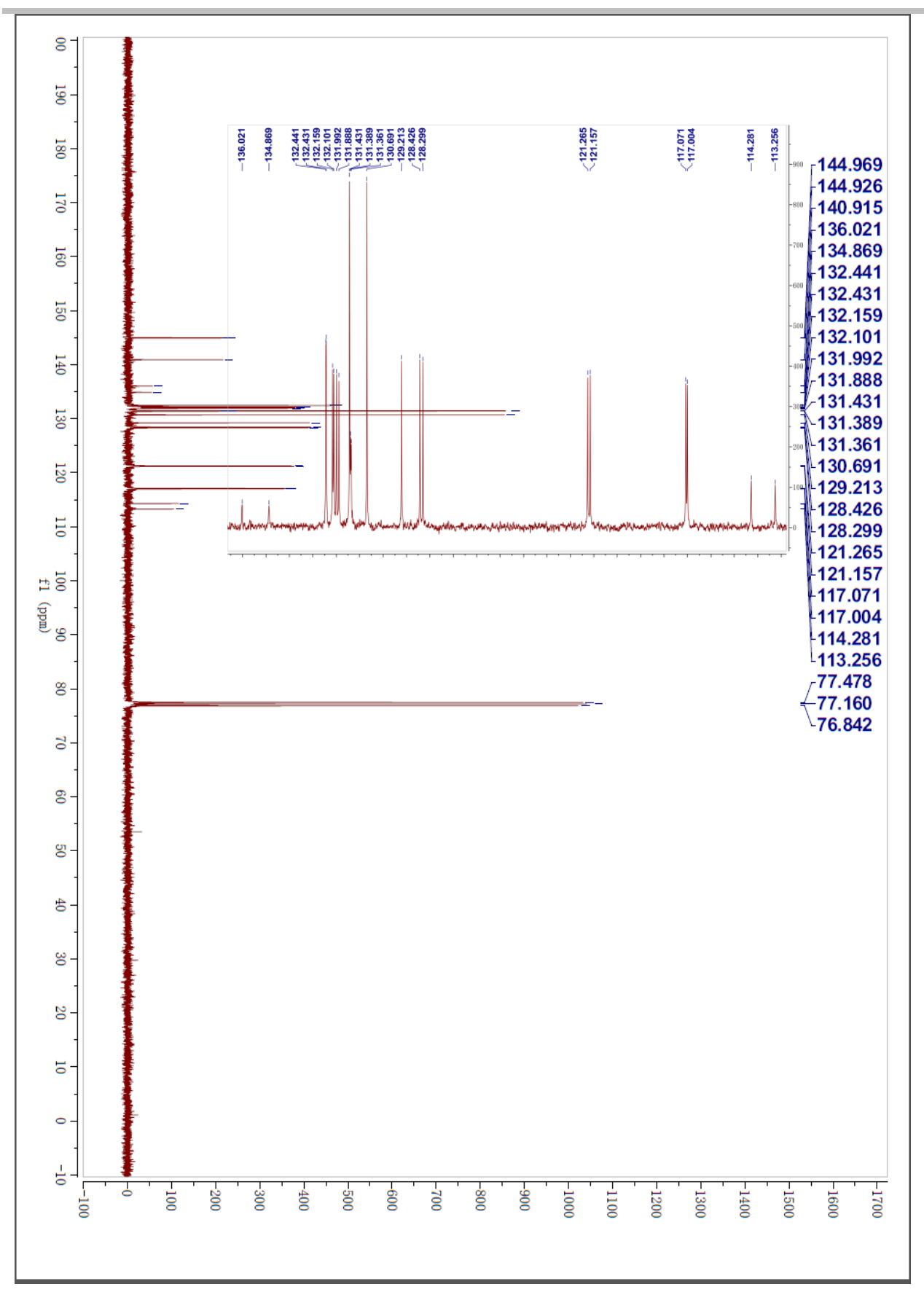




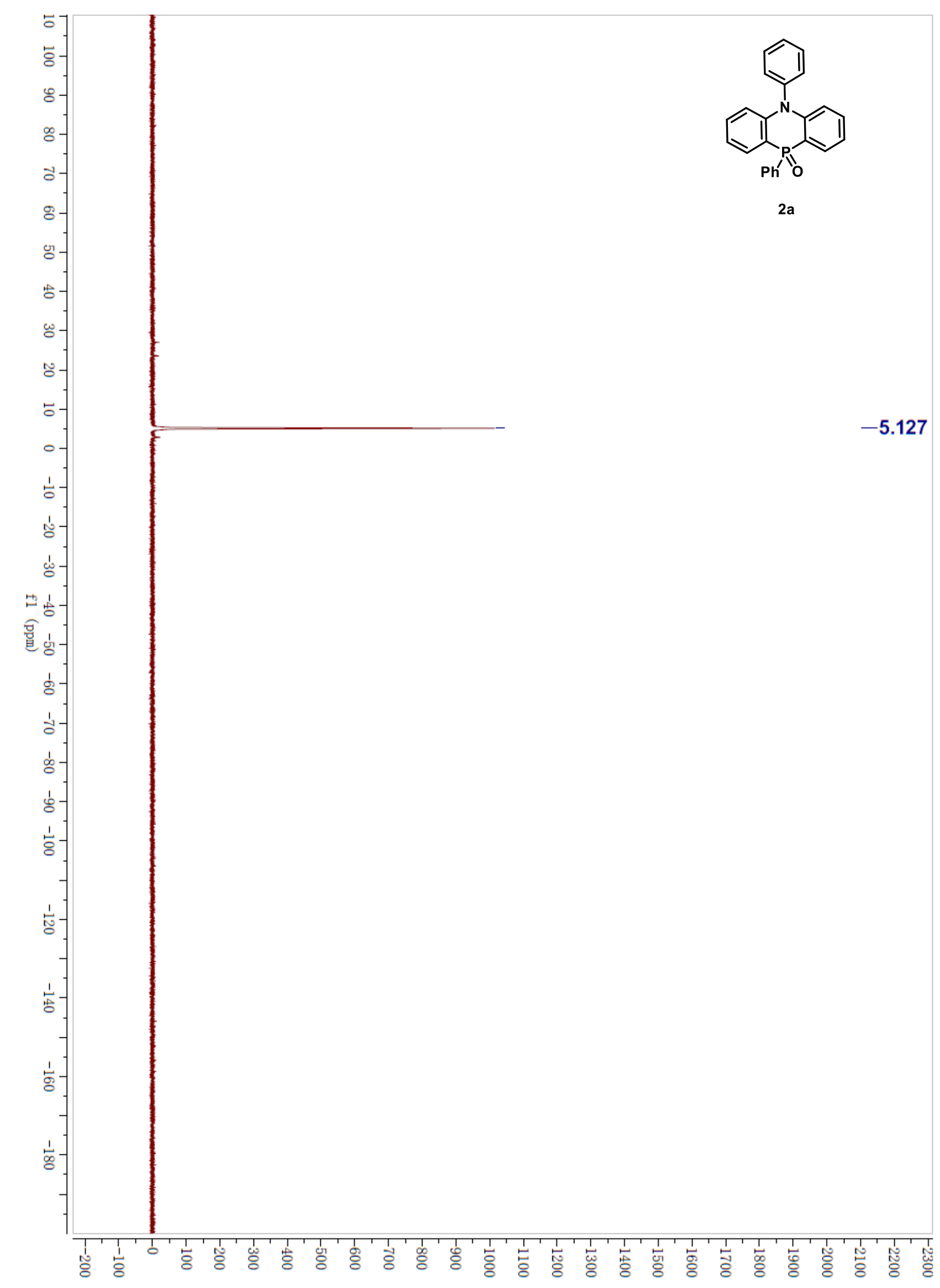




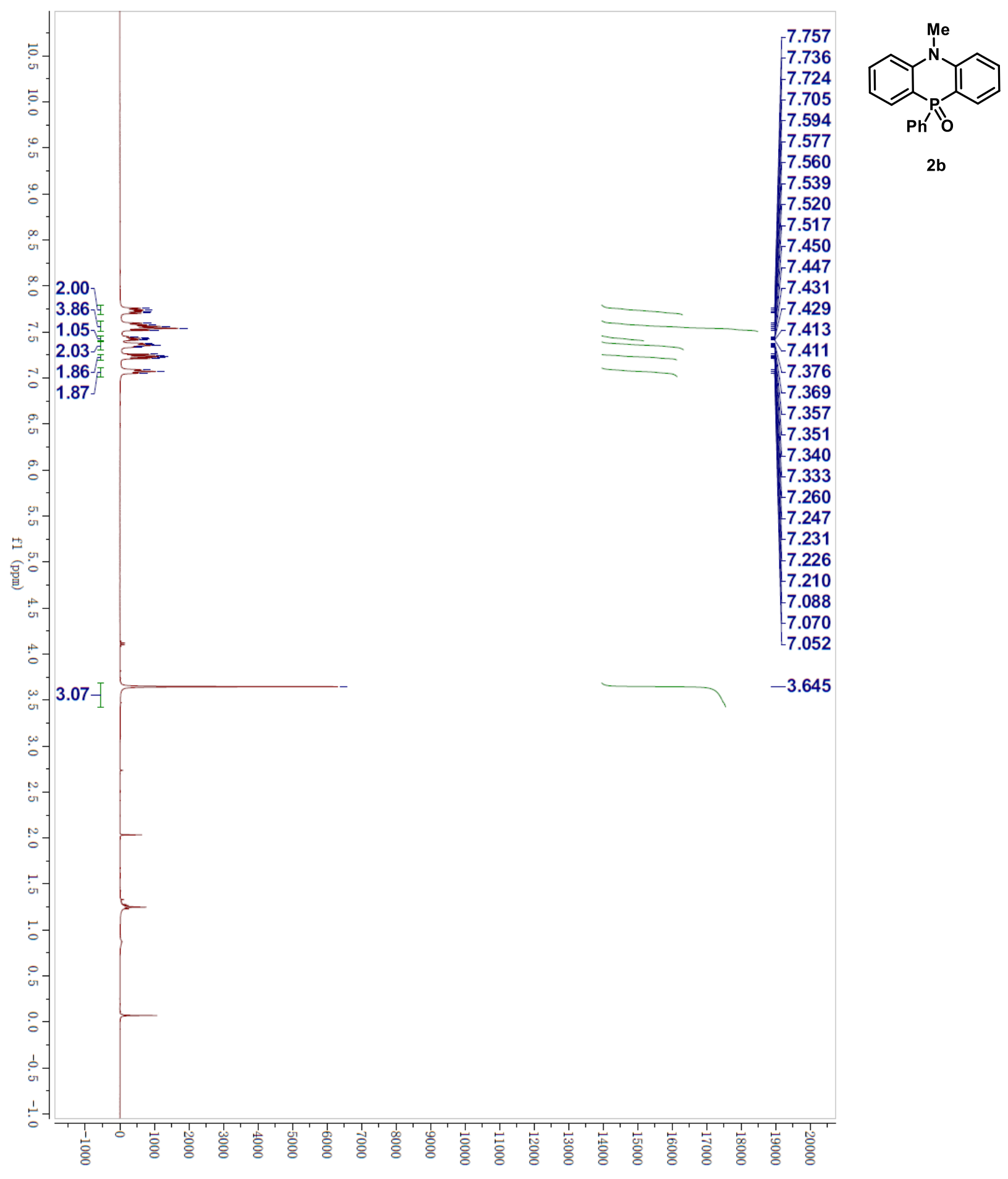




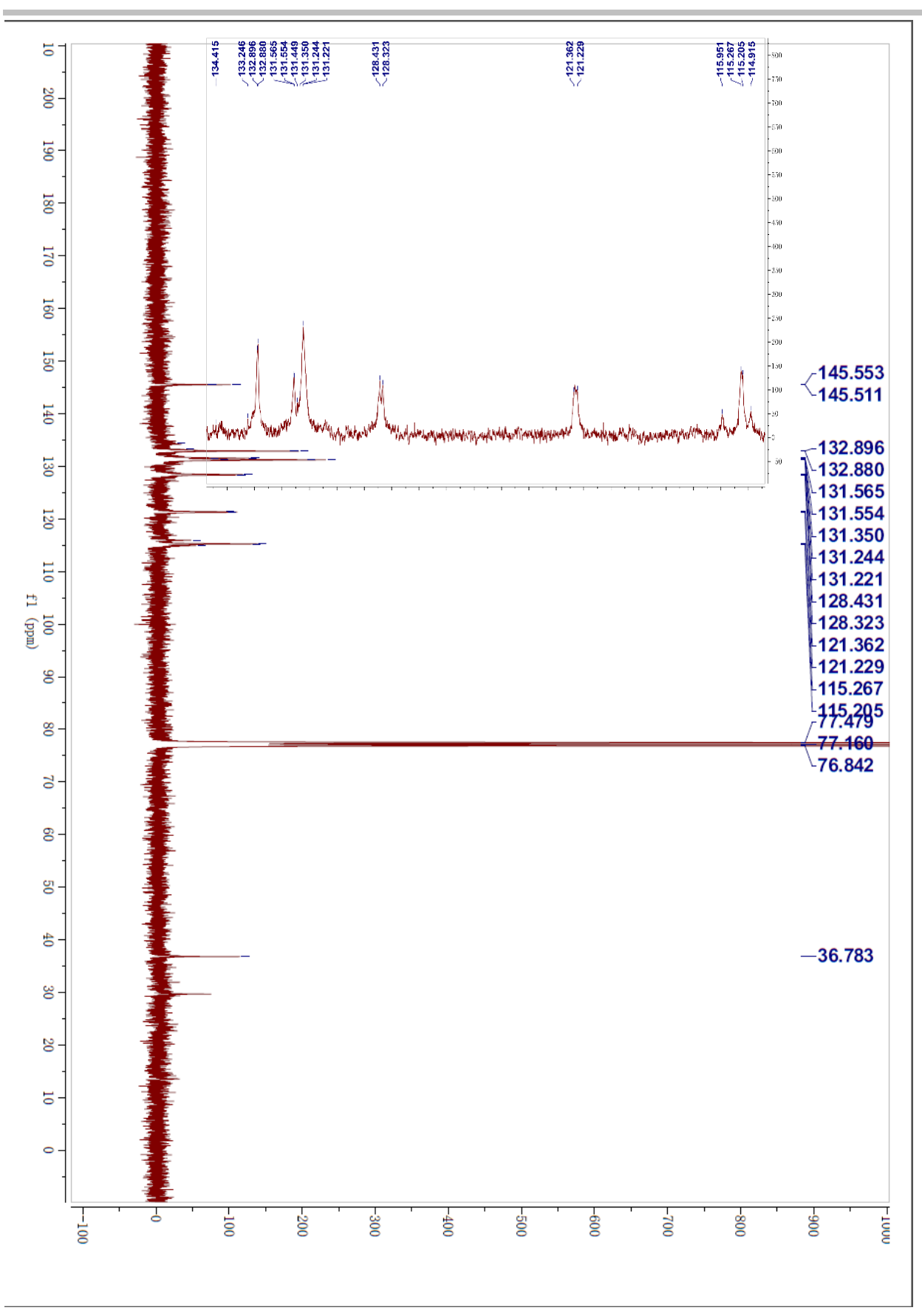




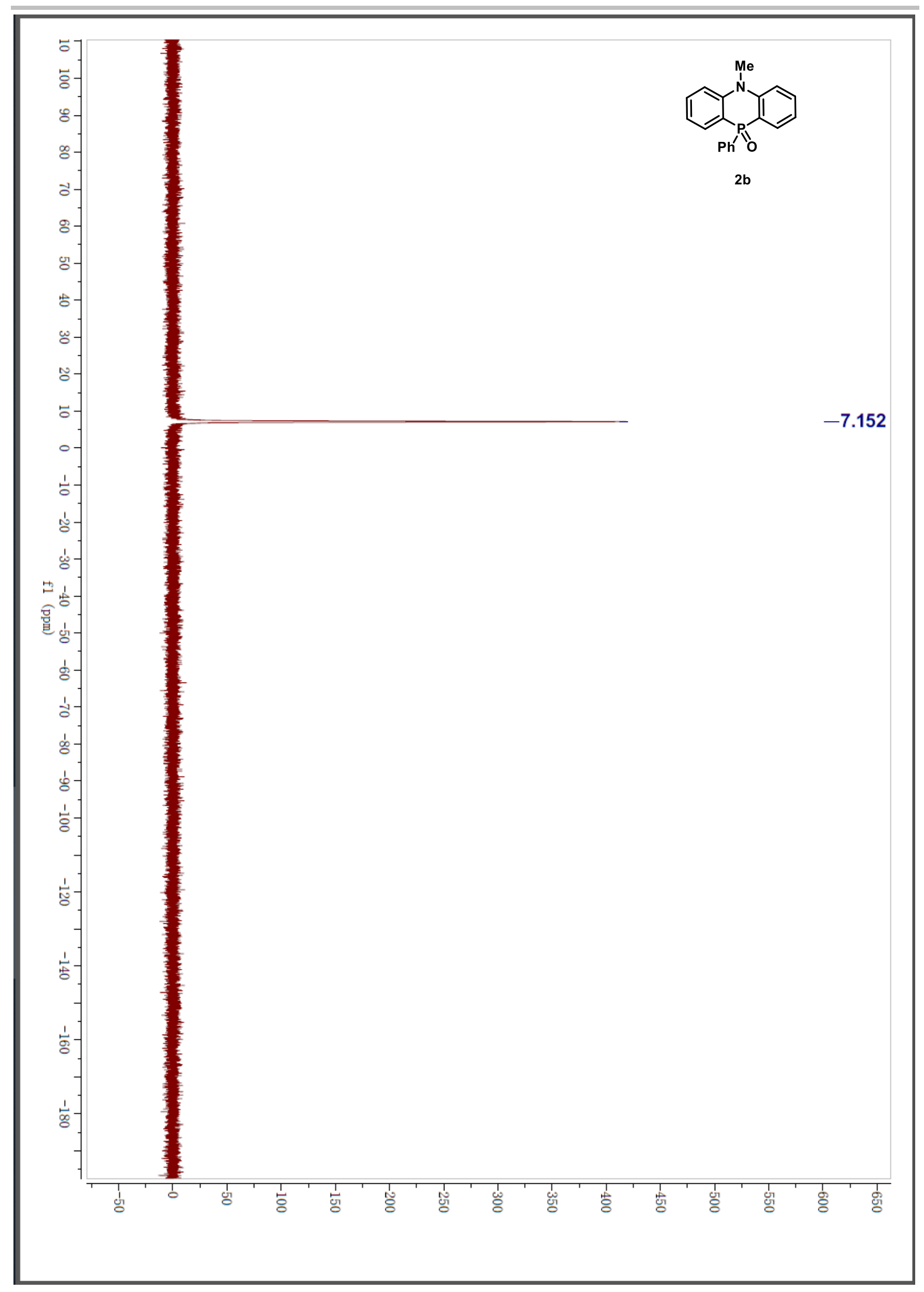




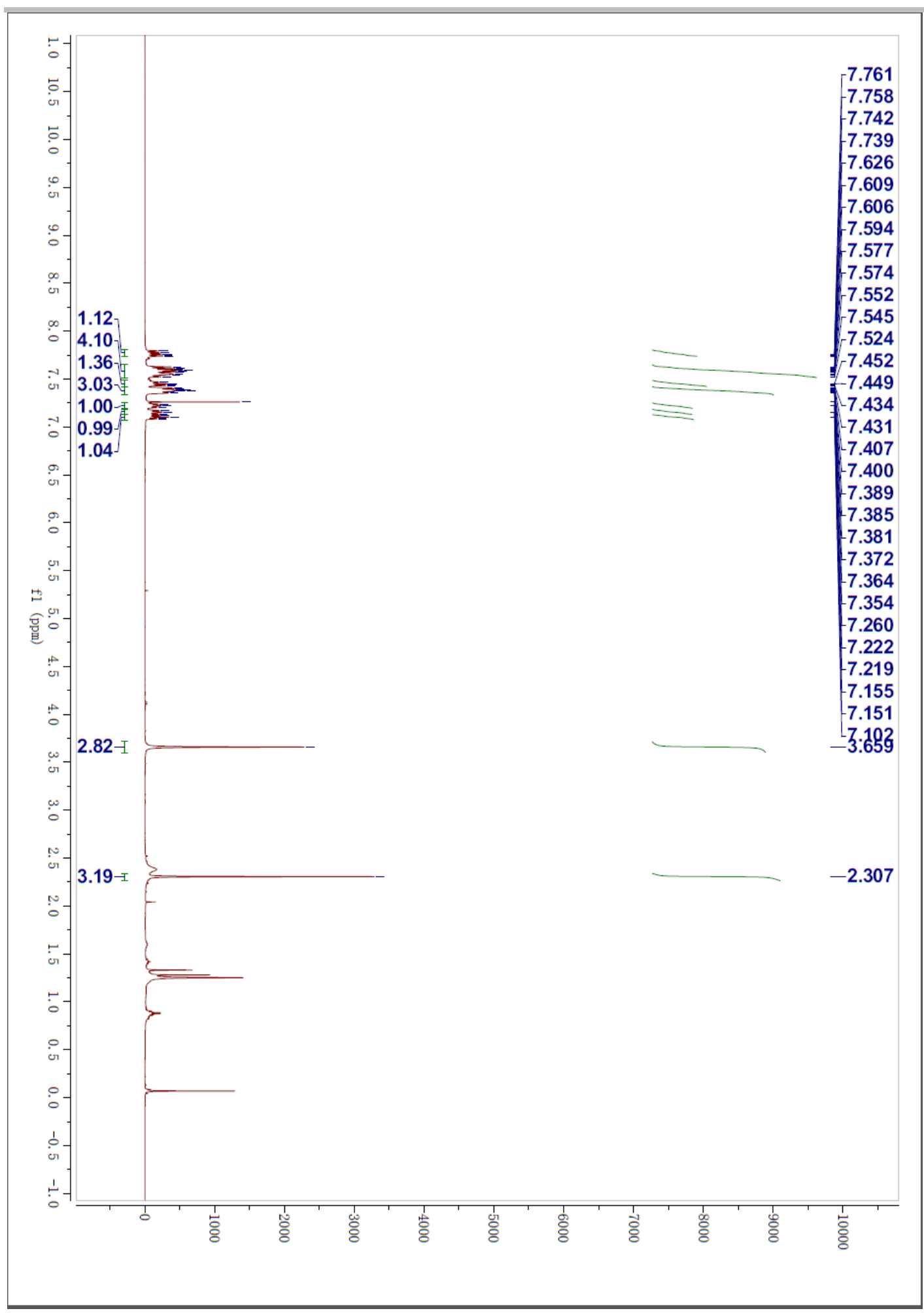




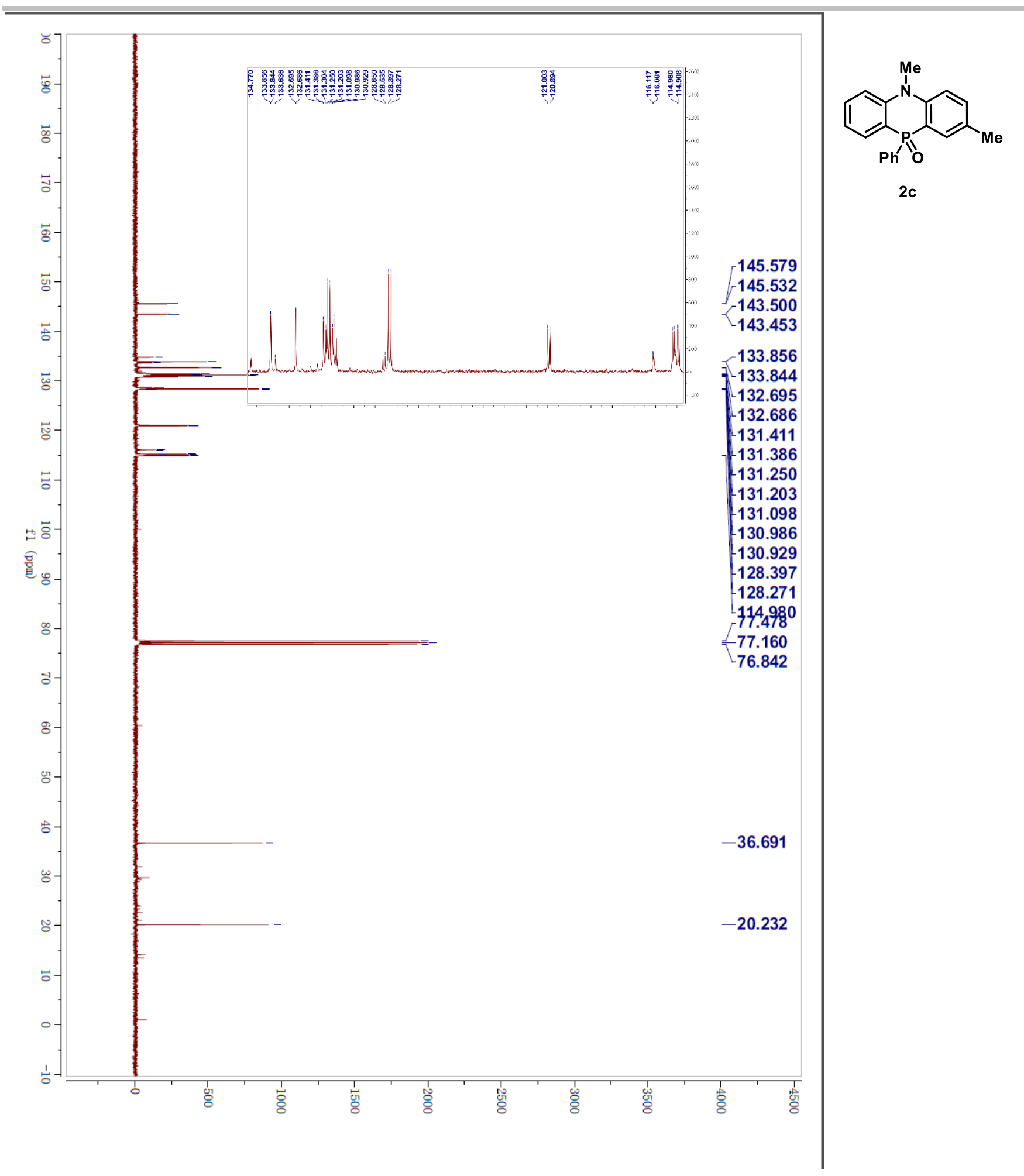




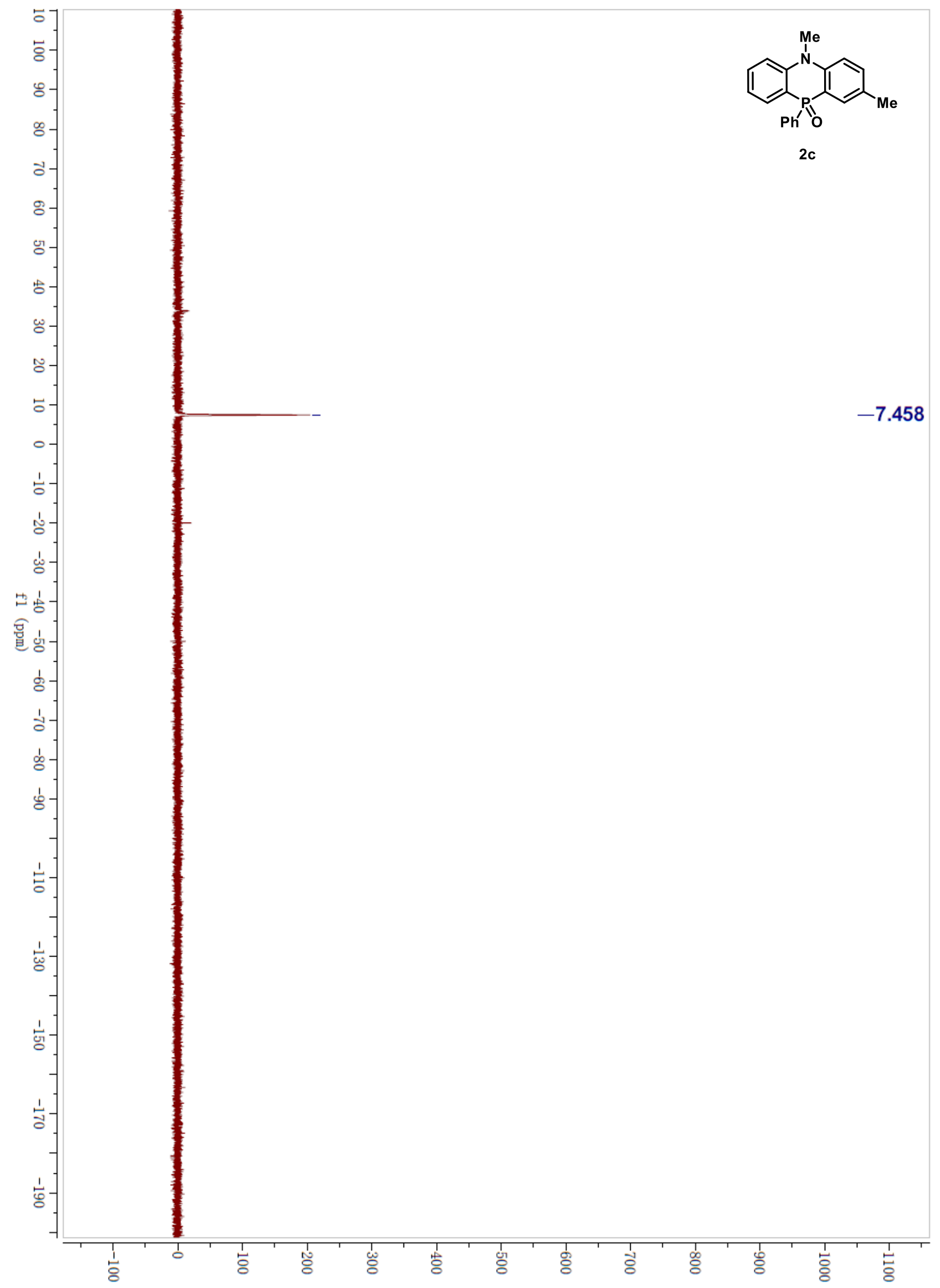




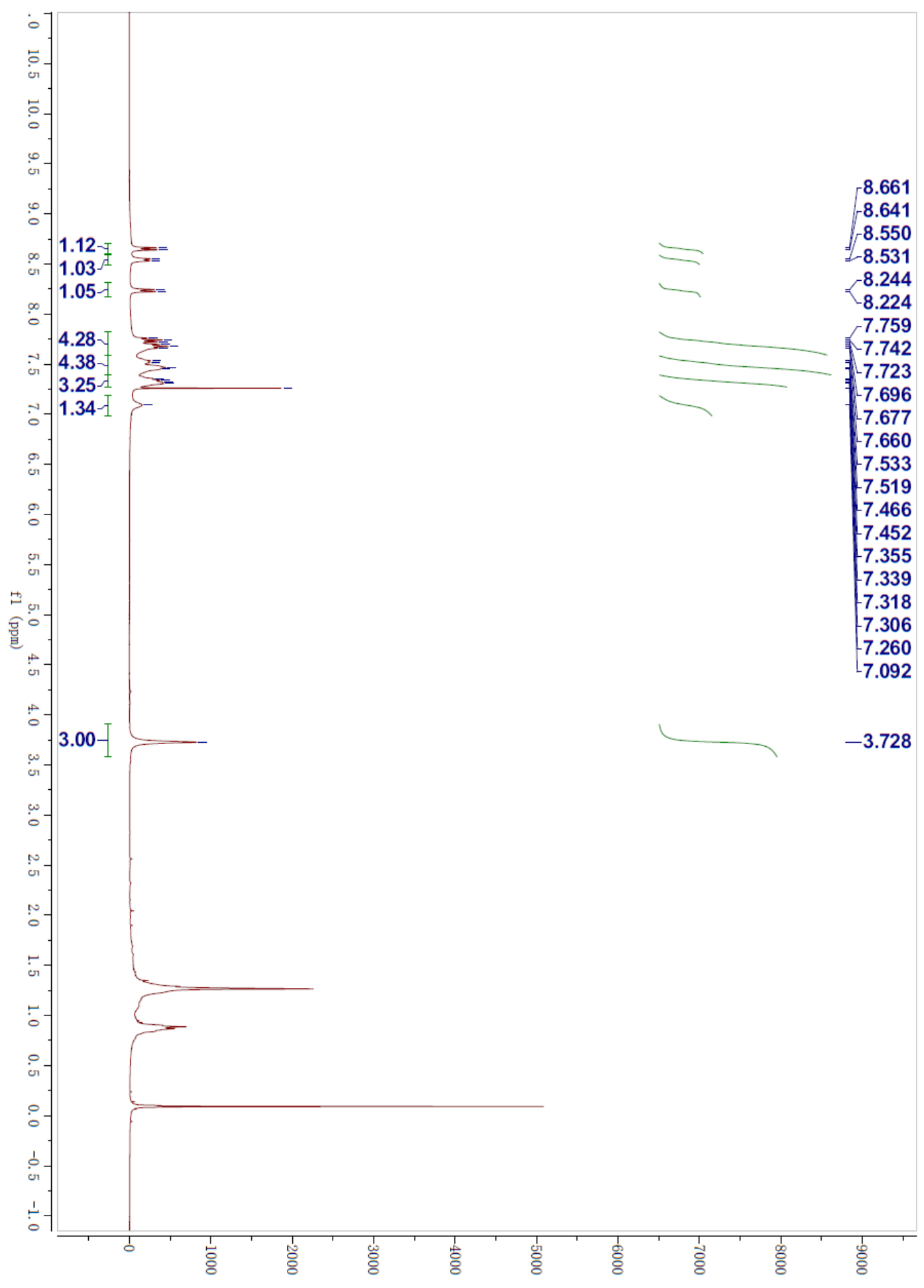

2d 


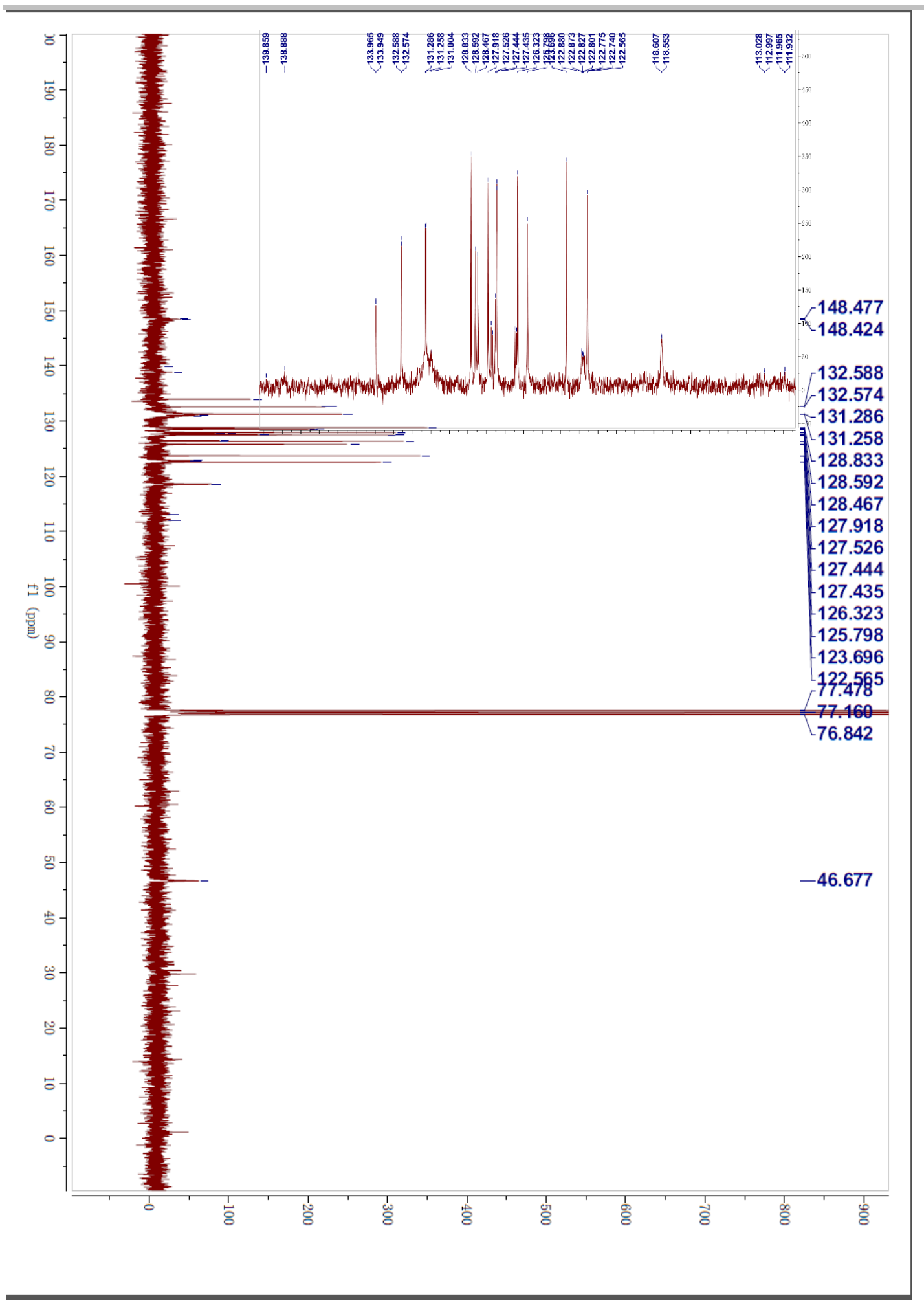<smiles>CN1c2c(c3ccccc3c3ccccc23)N(c2ccccc2P(=O)(O)c2ccccc2)S1(=O)=O</smiles>

2d 


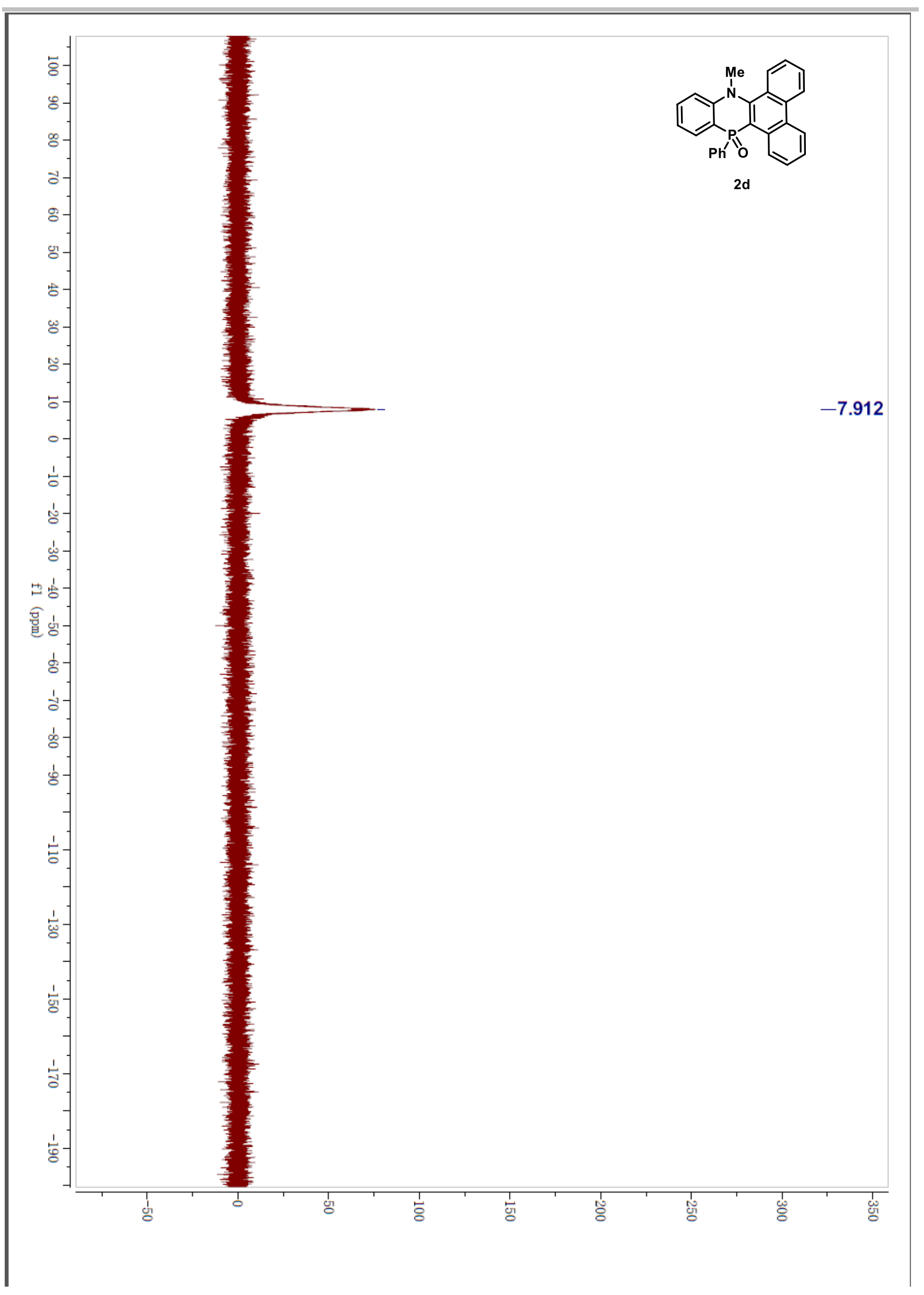




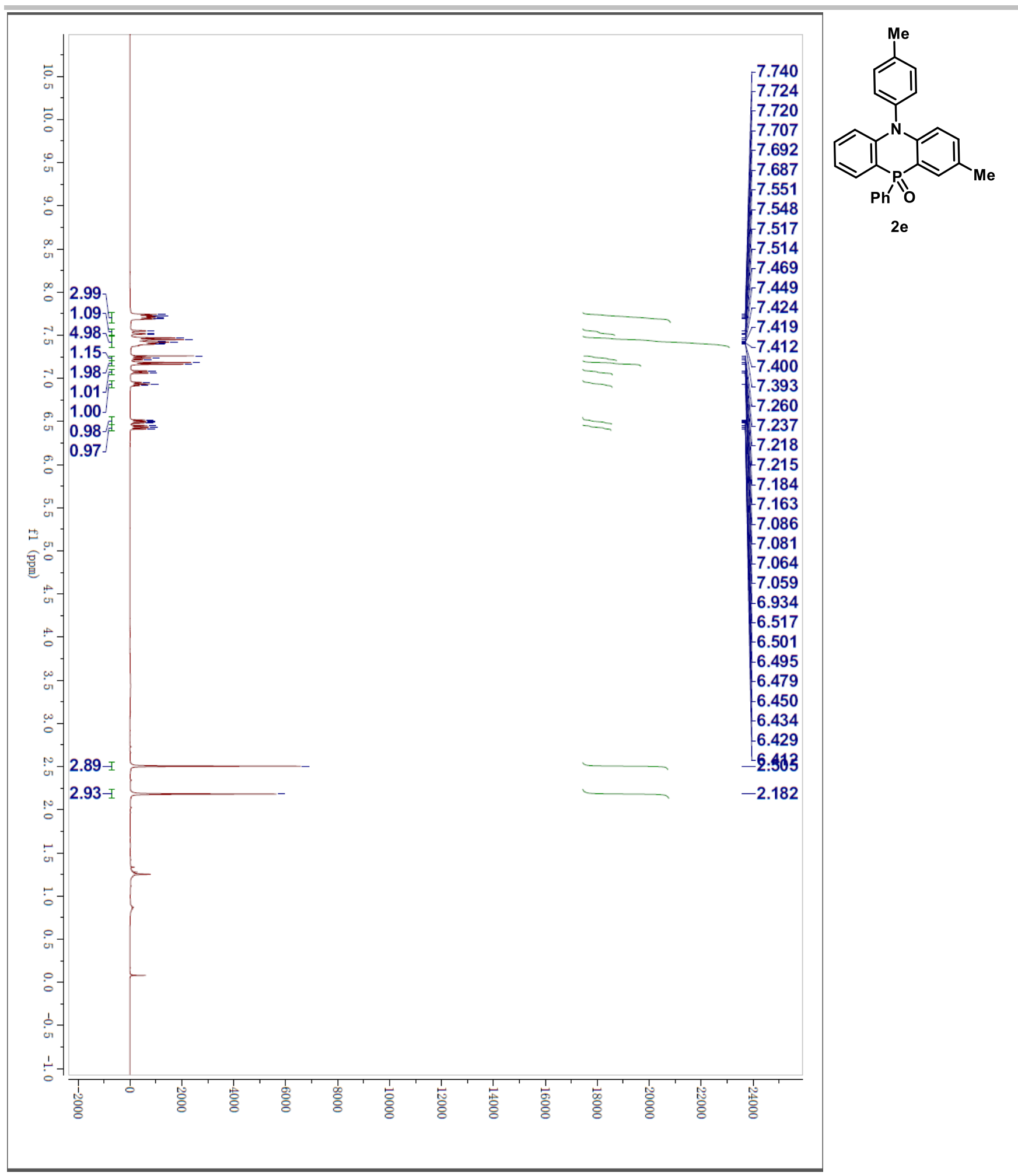




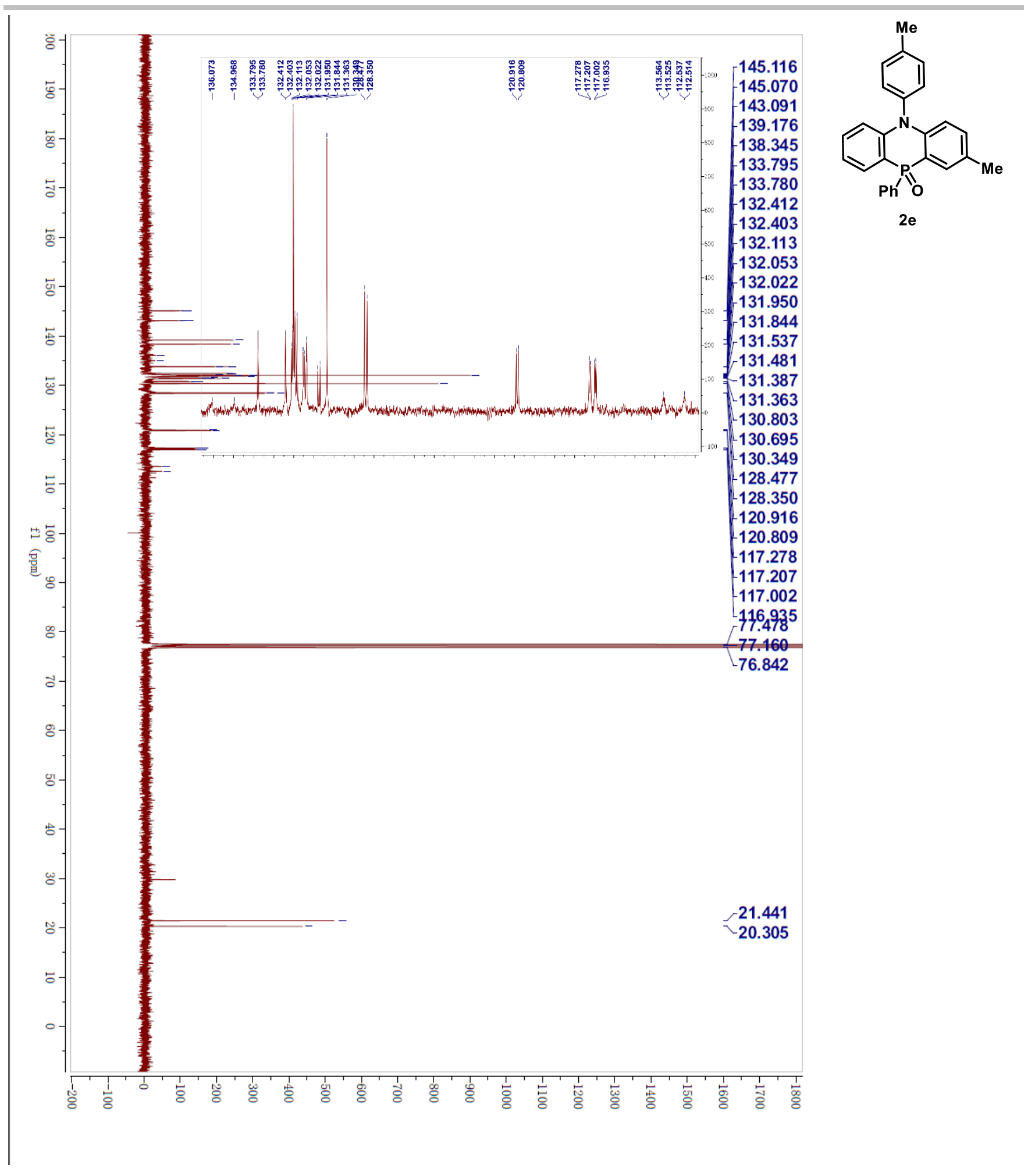




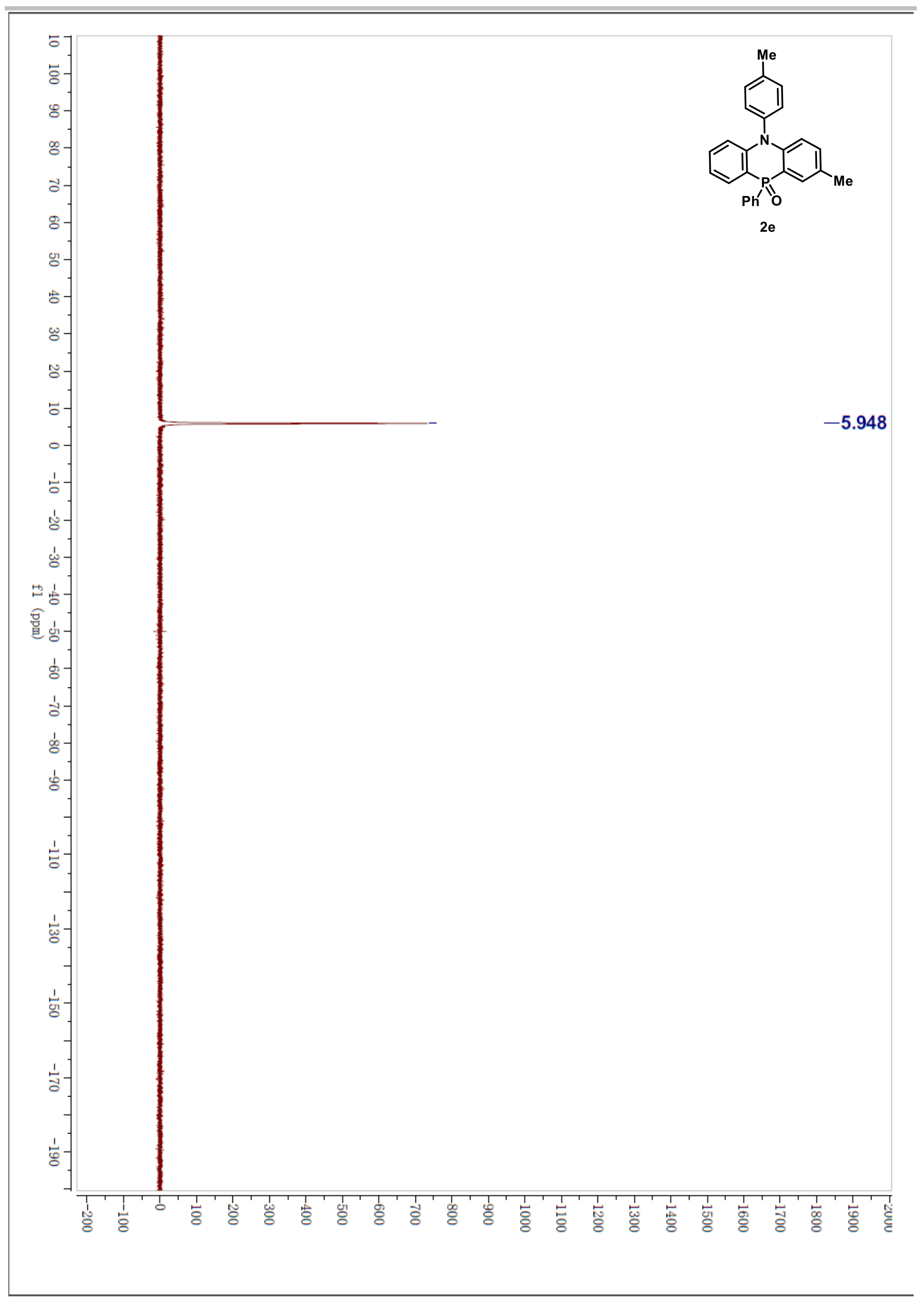




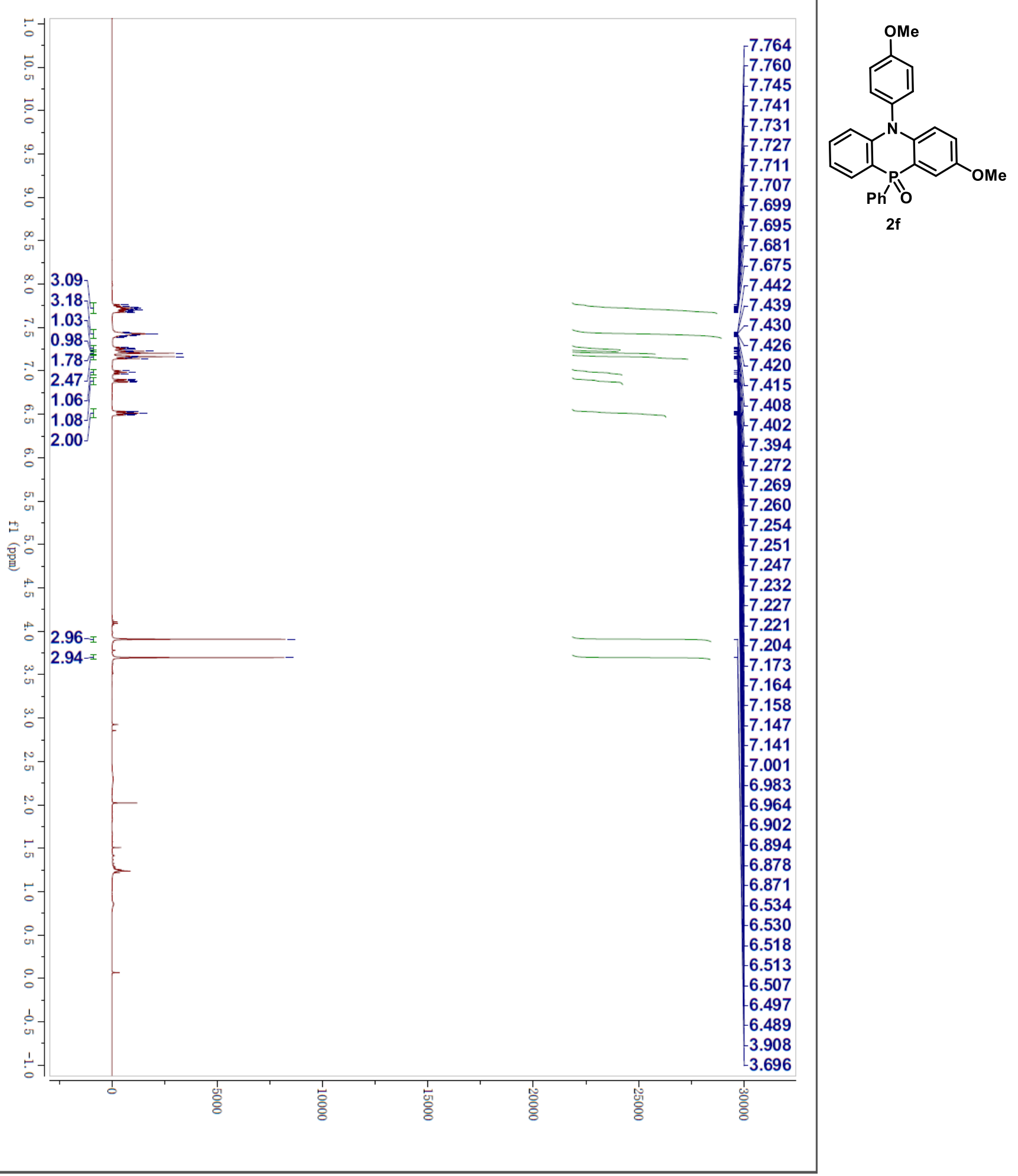




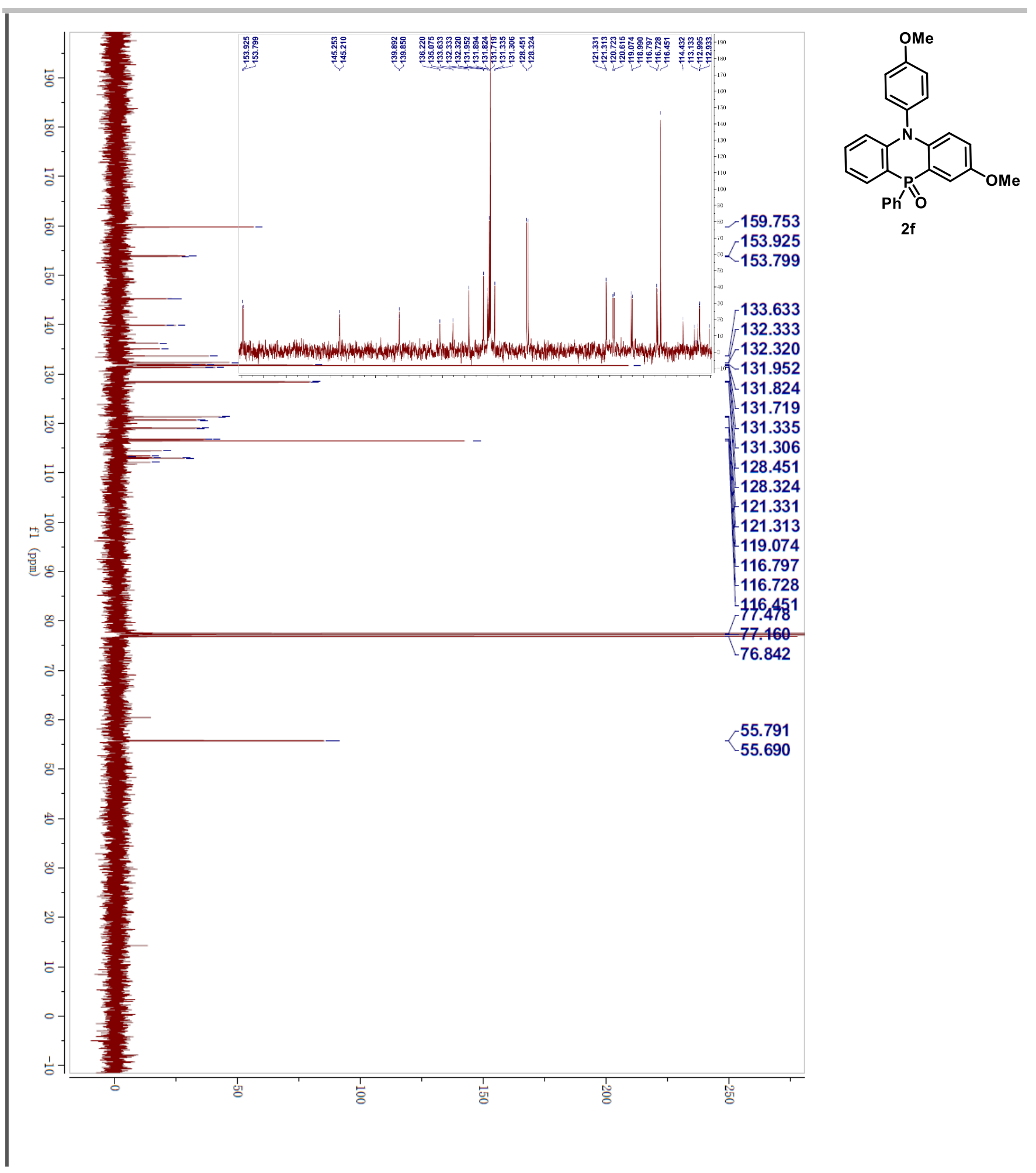




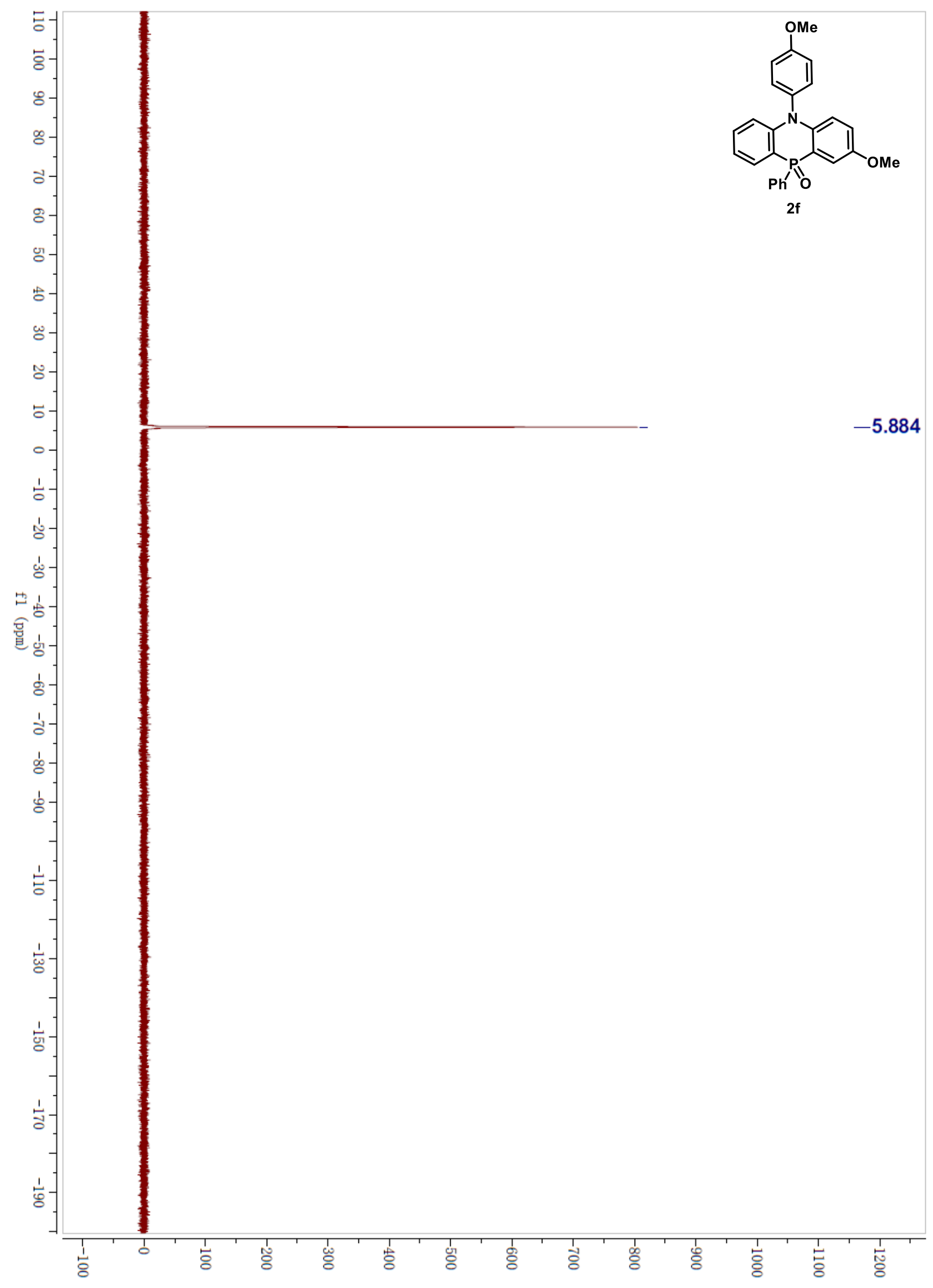




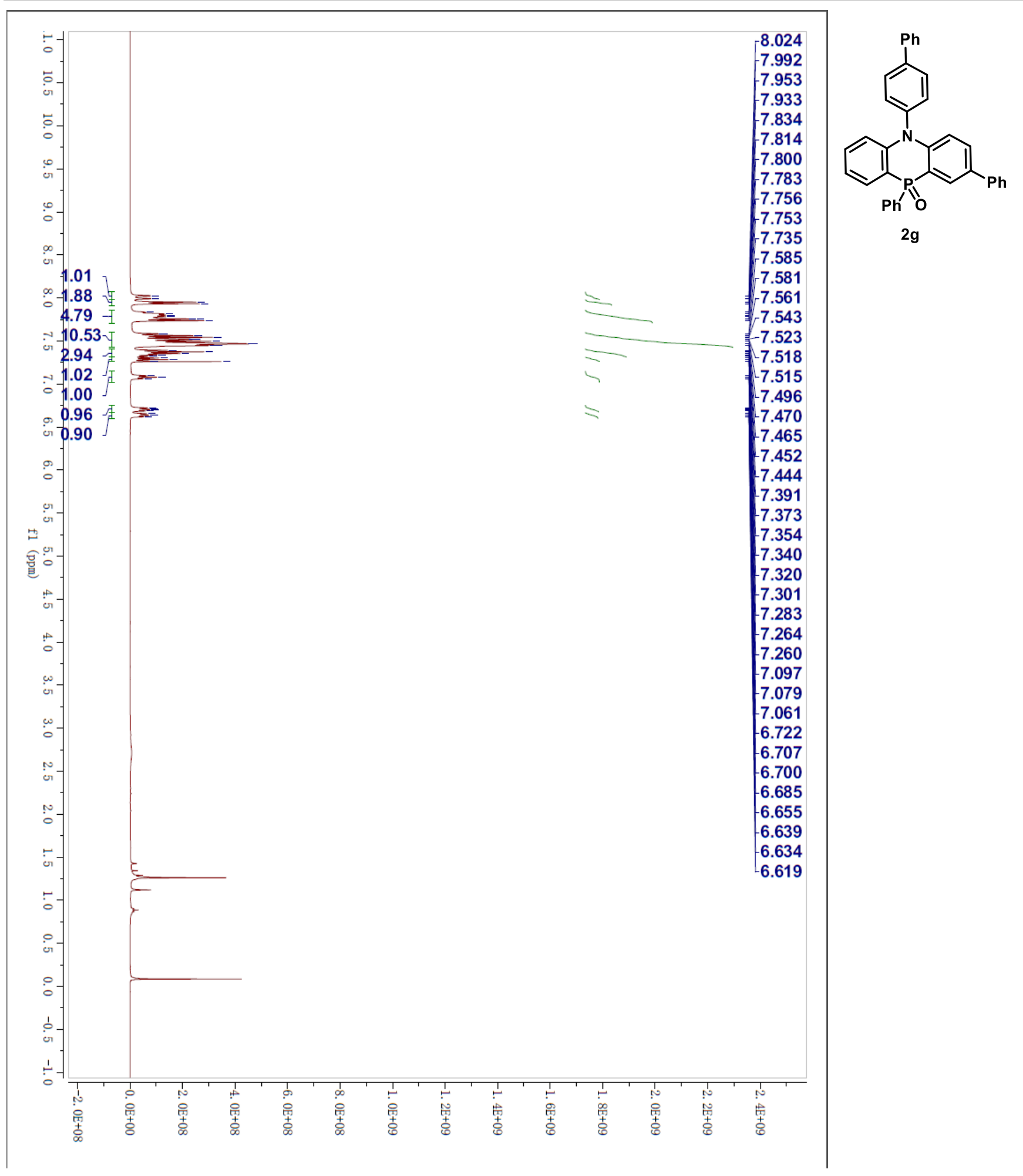




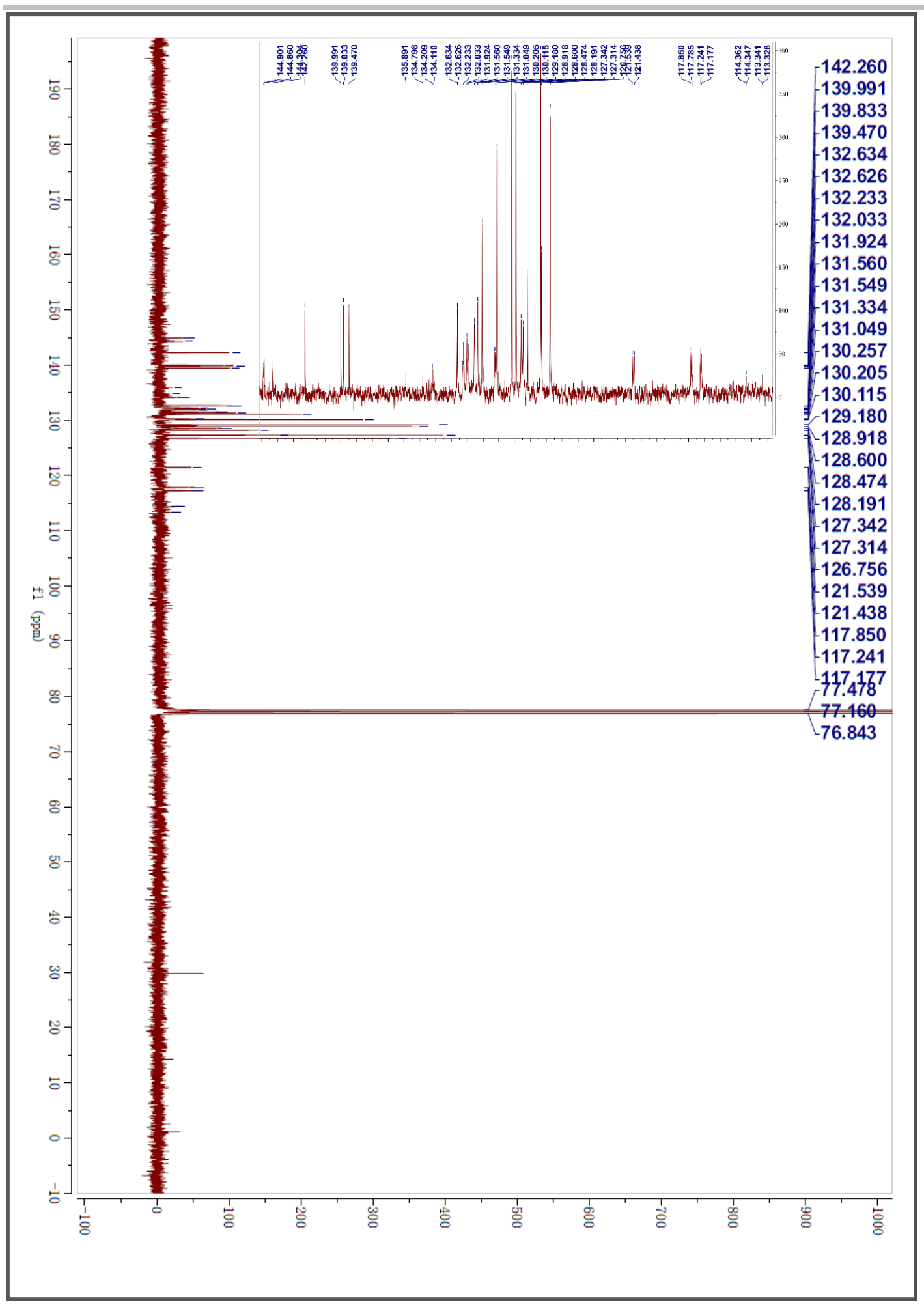




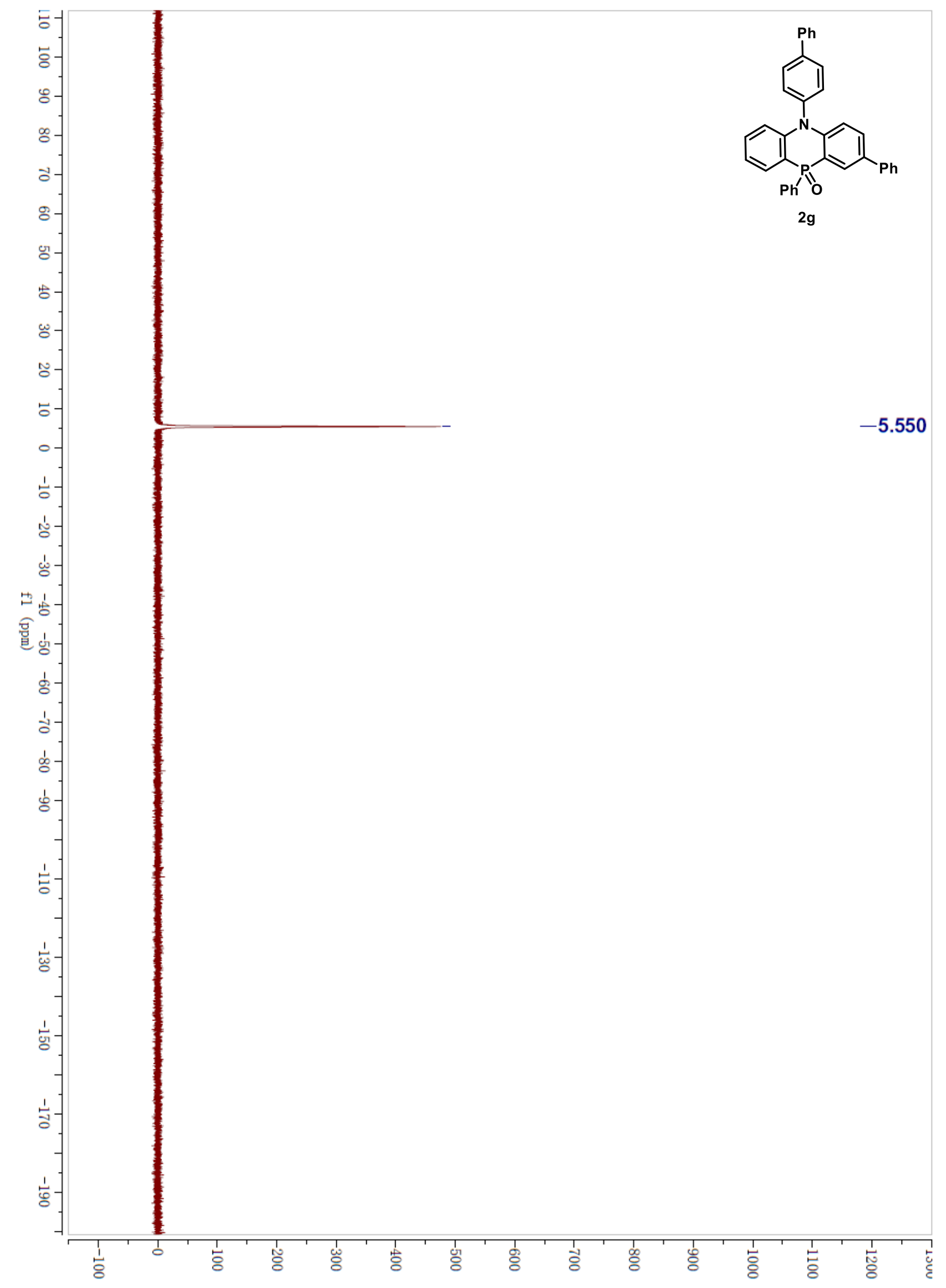



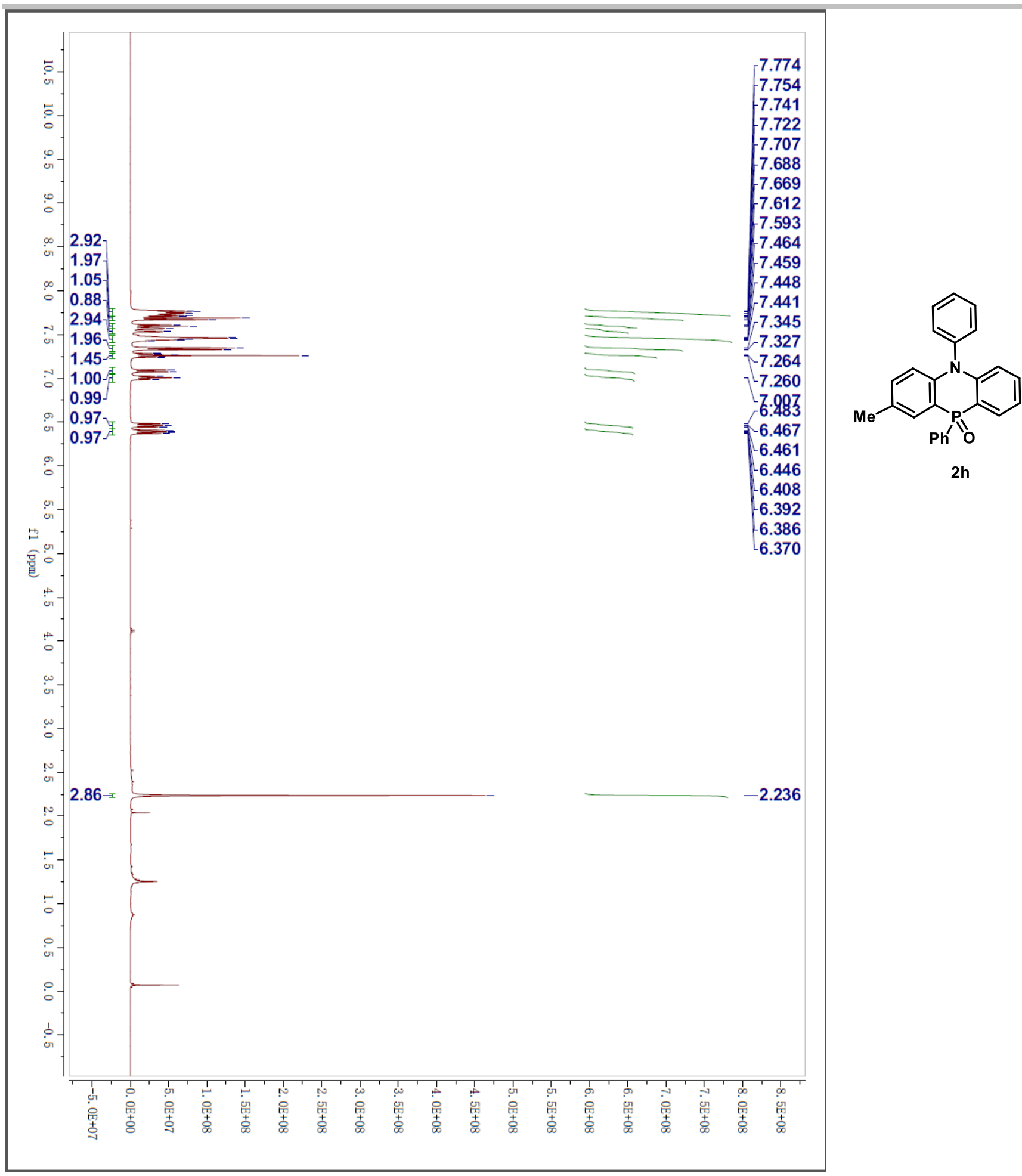

2h 


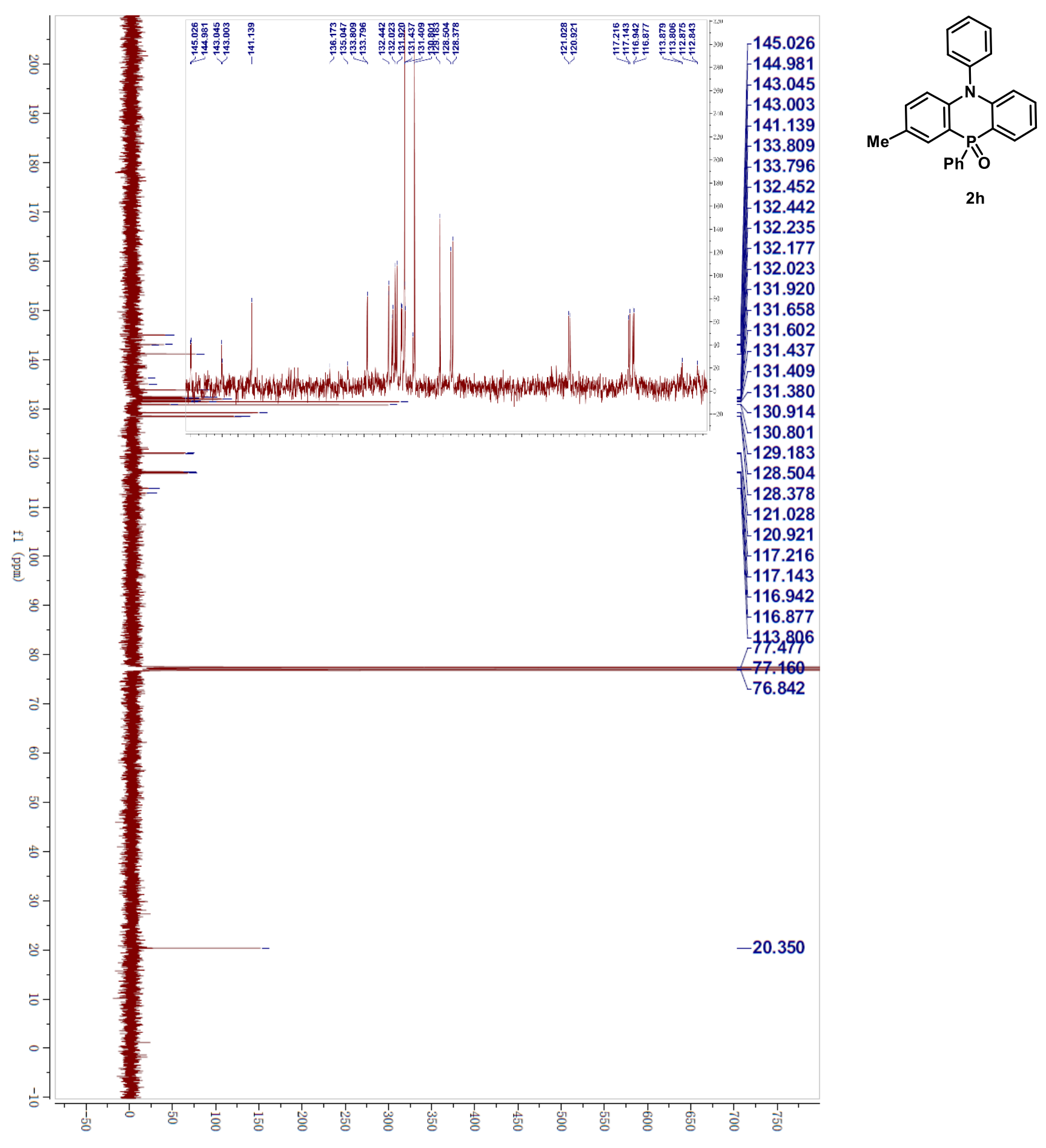




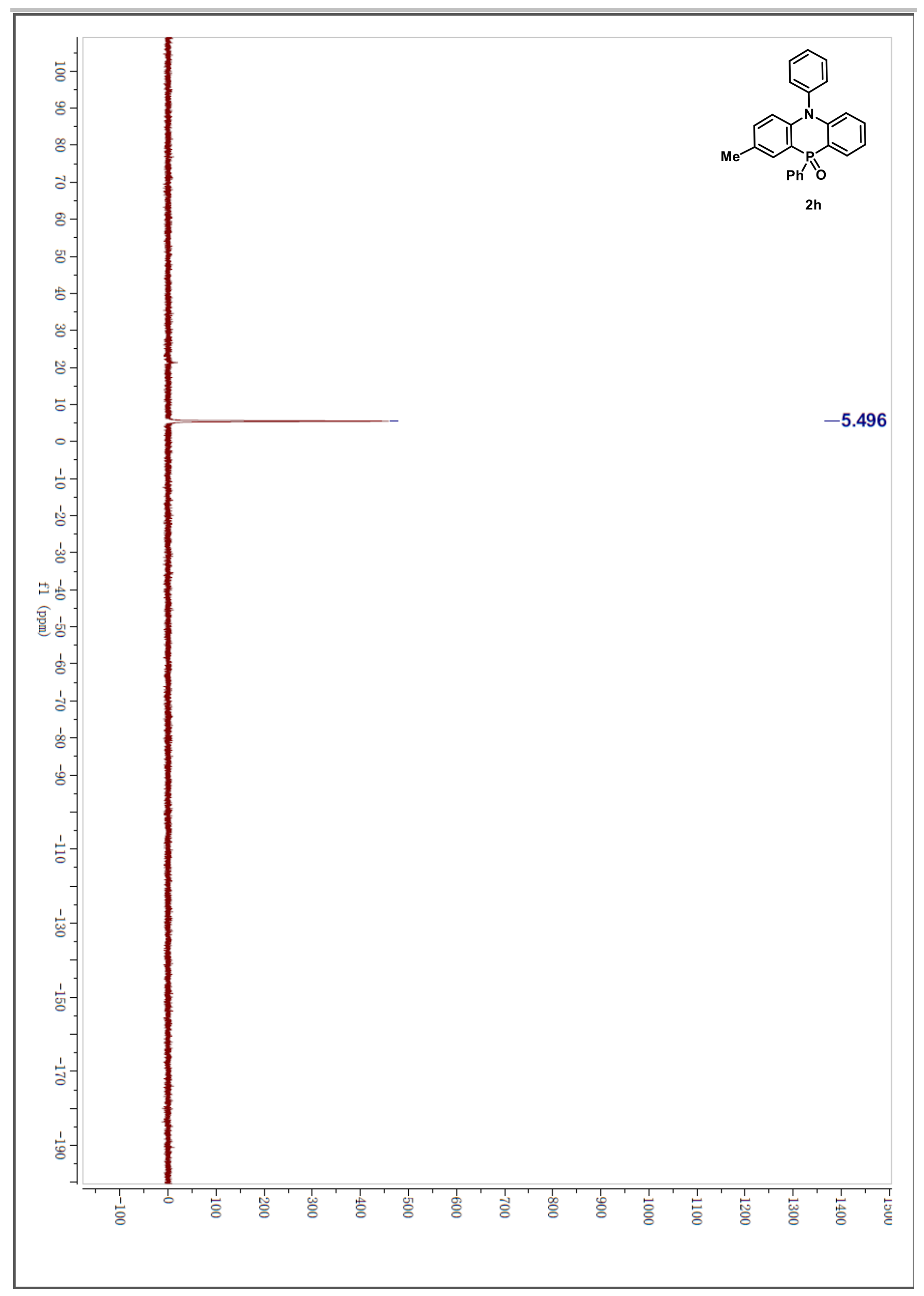




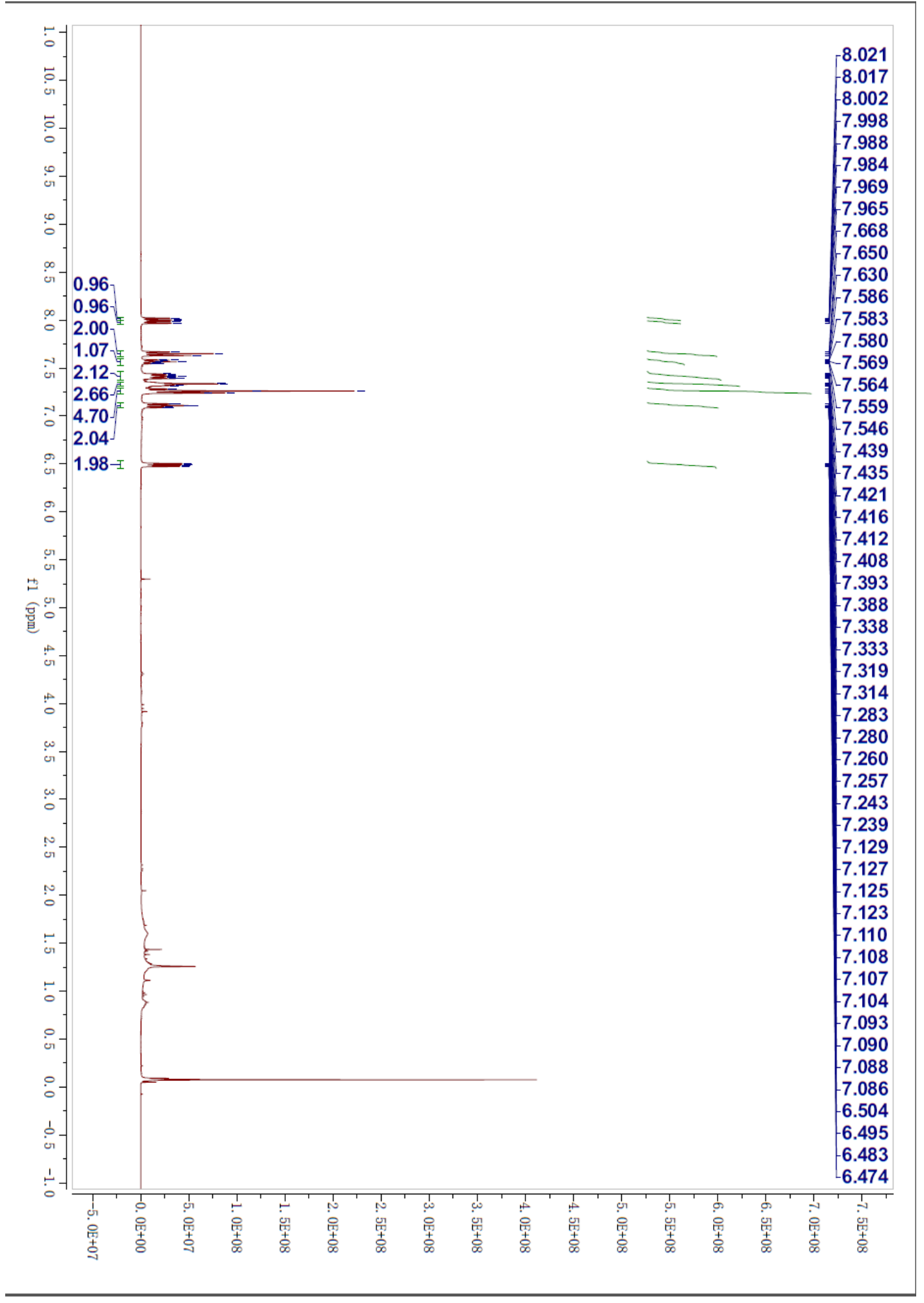




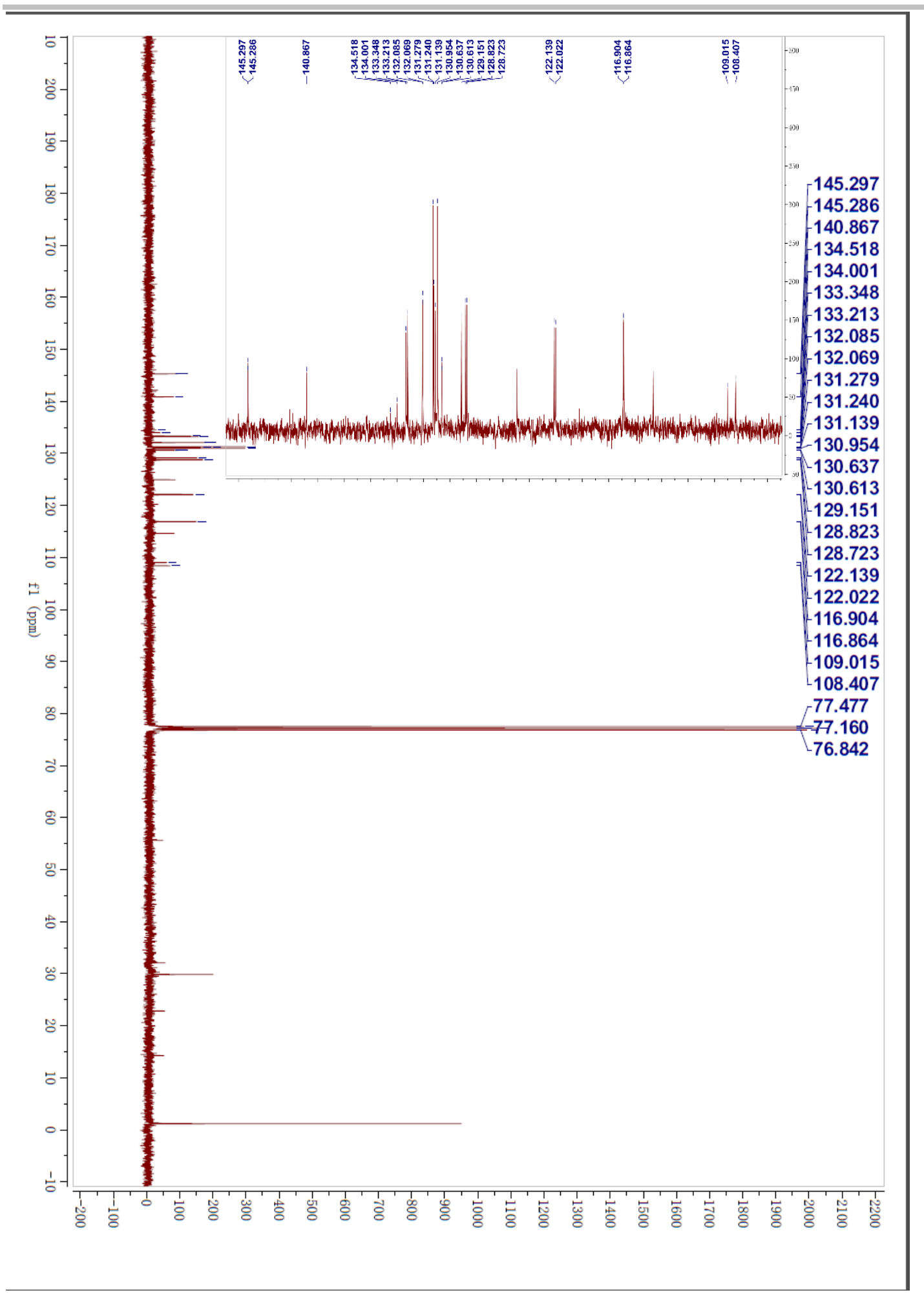




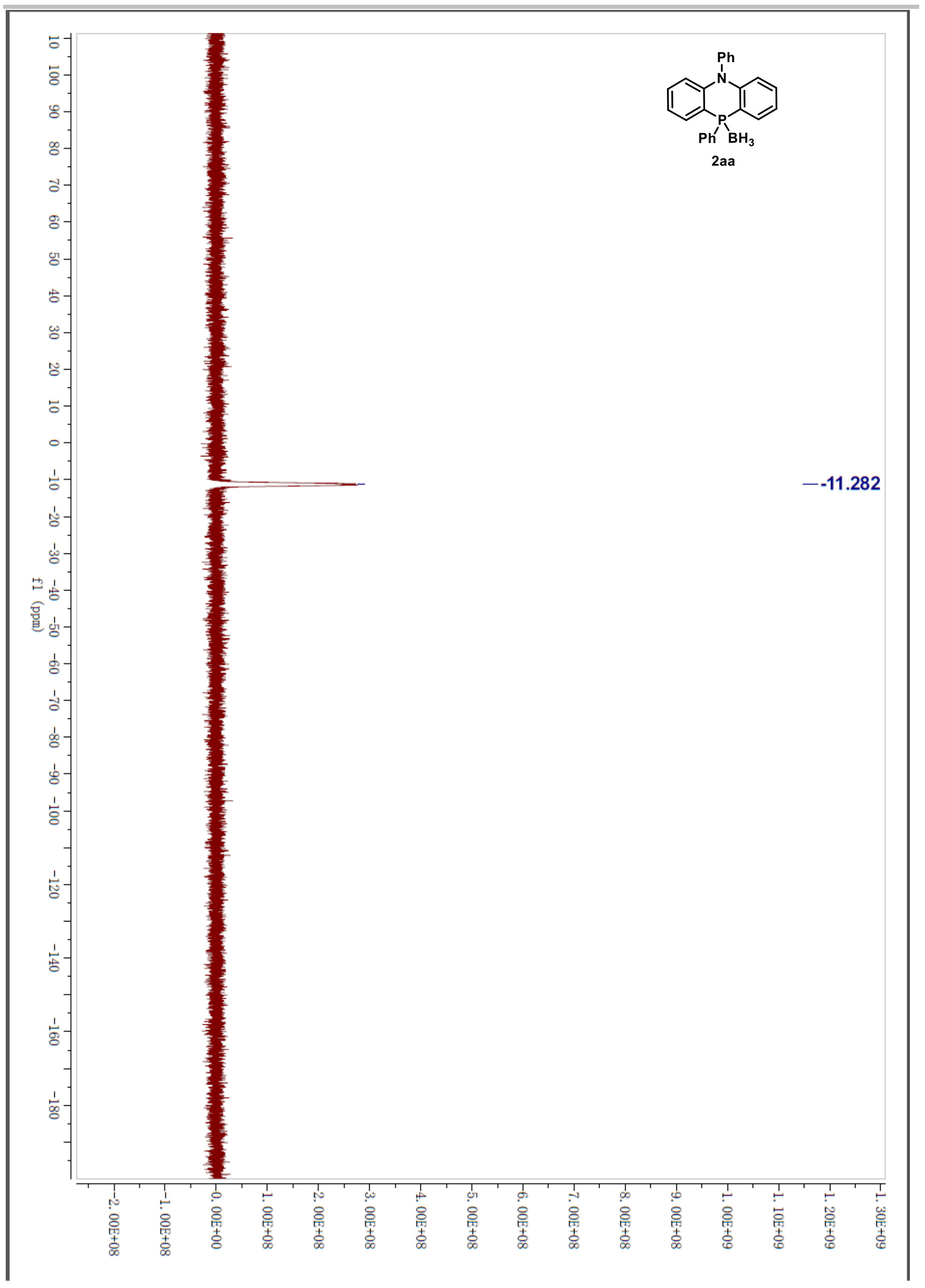

